OPEN ACCESS

Edited by:

Irene Stefanini,

University of Turin, Italy

Reviewed by:

Delphine Sicard,

Institut National de la Recherche Agronomique Centre Montpellier,

France

Francisco A. Cubillos,

University of Santiago, Chile

*Correspondence:

Caiti Smukowski Heil

cheil@ncsu.edu

Specialty section:

This article was submitted to

Evolutionary and Genomic

Microbiology,

a section of the journal

Frontiers in Genetics

Received: 17 July 2020

Accepted: 13 October 2020

Published: 11 November 2020

Citation:

Lahue C, Madden AA, Dunn RR and Smukowski Heil C (2020) History and Domestication of Saccharomyces

cerevisiae in Bread Baking.

Front. Genet. 11:584718.

doi: 10.3389/fgene.2020.584718

\section{History and Domestication of Saccharomyces cerevisiae in Bread Baking}

\author{
Caitlin Lahue 1,2, Anne A. Madden², Robert R. Dunn ${ }^{2,3}$ and Caiti Smukowski Heil1* \\ ${ }^{1}$ Department of Biological Sciences, North Carolina State University, Raleigh, NC, United States, ${ }^{2}$ Department of Applied \\ Ecology, North Carolina State University, Raleigh, NC, United States, ${ }^{3}$ Center for Evolutionary Hologenomics, The GLOBE \\ Institute, University of Copenhagen, Copenhagen, Denmark
}

The yeast Saccharomyces cerevisiae has been instrumental in the fermentation of foods and beverages for millennia. In addition to fermentations like wine, beer, cider, sake, and bread, S. cerevisiae has been isolated from environments ranging from soil and trees, to human clinical isolates. Each of these environments has unique selection pressures that $S$. cerevisiae must adapt to. Bread dough, for example, requires $S$. cerevisiae to efficiently utilize the complex sugar maltose; tolerate osmotic stress due to the semi-solid state of dough, high salt, and high sugar content of some doughs; withstand various processing conditions, including freezing and drying; and produce desirable aromas and flavors. In this review, we explore the history of bread that gave rise to modern commercial baking yeast, and the genetic and genomic changes that accompanied this. We illustrate the genetic and phenotypic variation that has been documented in baking strains and wild strains, and how this variation might be used for baking strain improvement. While we continue to improve our understanding of how baking strains have adapted to bread dough, we conclude by highlighting some of the remaining open questions in the field.

Keywords: Saccharomyces cerevisiae (Baker's yeast), bread, baking, domestication, industrial, yeast

\section{INTRODUCTION}

Bread baking in the home has experienced a surge in interest in recent years, heightened during mandatory stay at home orders during the COVID-19 pandemic (McCarron, 2020). Grocery store shelves were emptied of flours and commercial yeast (Mak and Slate Magazine, 2020), and thousands of people began sourdough starters, using spontaneous inoculation of yeast in bread and water (Aviles, 2020; Nichols, 2020). This trend in home baking comes on the heels of an increasing desire from commercial bakers to use different types of grains and to develop more interesting, complex flavors in their baked products (Glover et al., 2010; Steensels and Verstrepen, 2014). A similar phenomenon has occurred in the craft brewing industry, which has led to an explosion of research into the history of commercial brewing strains and the use of alternative yeasts (Gallone et al., 2016, 2019; Fay et al., 2019; Langdon et al., 2019). However, the yeasts used for bread baking have received considerably less attention than their beer and wine making cousins.

Leavened bread is made via two main processes. The first is the addition of commercial baker's yeast, Saccharomyces cerevisiae, to dough. This yeast comes from pure cultures bought (or more rarely maintained) by bakers and bakeries. The second is the creation and maintenance of a "starter," 
by allowing yeasts and bacteria to spontaneously inoculate a mix of milled grains (e.g., flour) and water. Such starters can be very old, having been passed from one human generation to the next, but many are made from scratch in the kitchen of the baker. The inoculating yeast in starters can be a mix of commercial or domesticated strains, such as S. cerevisiae, and/or environmental (or "wild") strains which are undomesticated and found in non-human related environments (Johnson et al., 2004; De Vuyst and Neysens, 2005).

The first process, the use of commercial yeast, is dominated by a small handful of $S$. cerevisiae strains, such as those manufactured by Fleischmann's, Red Star, and SAF. The second process, reliance on starters, is more complex and varied. Starters are a rich microbial community, the composition of which can vary due to human culture, geography, individual baker, type of grains used, timing of sampling in the starter's history, and many other factors (Minervini et al., 2012; Ercolini et al., 2013; De Vuyst et al., 2014, 2016; Carbonetto et al., 2018). Different yeast species are found in different starters. However, S. cerevisiae are present in the majority of sampled sourdough starters. The strain diversity of $S$. cerevisiae in starters is largely unknown, particularly in breads from nonWestern cultures (Pulvirenti et al., 2004; Vrancken et al., 2010; Lhomme et al., 2016).

In light of a renewed excitement from home and commercial bakers, combined with new insights from increased worldwide sampling and whole genome sequencing, we seek to highlight the genetic basis of $S$. cerevisiae adaptation to dough, both in the context of commercial yeasts and sourdough starters. Much of this review is filtered through the lens of European history and baking strains, which gave rise to several of the commercial baking strains used today. With that caveat, the emphasis of this paper is to catalog known genetic differences between bakery strains of $S$. cerevisiae compared to wild and other industrial strains. We start with a brief history of risen bread and baking yeast domestication. We focus on the particular conditions that bread yeast face, and the key genes and pathways known to be important in these conditions with a particular concentration on maltose utilization, osmotic stress tolerance, and aroma production. We conclude with a look at methods of bioprospecting and bioengineering for better baking, and key questions that the field can address moving forward.

\section{THE RISE OF BAKING: A BRIEF HISTORY OF BREAD}

Scientists tend to describe the discovery of the role of yeast in fermentation in relation to the visual discovery of the morphology of the yeast organisms by J. H. van den Broek in 1859 (Sicard and Legras, 2011). Yet, bakers have been using yeast for the production of food and beverages for thousands of years and, in doing so, were well aware of their reliance on living beings, which were very often named, even if their means of describing those beings was not the same as that now employed by later scientists. The earliest known records of yeast risen bread come from Ancient Egypt in 1300-1500 BCE
(Samuel, 1996; Sicard and Legras, 2011) and China in 500-300 BC (Shevchenko et al., 2014). However, it is likely that organized reliance on organisms for fermentation is far older. Amato and colleagues, for example, have recently argued that early hominins likely fermented fruits using yeasts, as early as a million years ago (Dunn et al., 2020). In this context, we suspect that the reliance on yeast for grain fermentation, including that associated with bread making, is much older than current dates based on archaeological samples. If, as has been frequently argued, beer and bread making pre-date the origin of agriculture, we might imagine that so too does increased reliance on specific yeasts. However, it is noteworthy that recent genomic evidence suggests that the canonical beer and bread yeast, $S$. cerevisiae, originated in China before moving west 16-14 tya via the route which would become the Silk Road (Wang et al., 2012; Duan et al., 2018; Peter et al., 2018; Fay et al., 2019). This is just before the origin of agriculture, roughly in line with the timing of the oldest bread yet documented (which might or might not have been leavened) (Arranz-Otaegui et al., 2018). This suggests that fermentations happening outside of Asia prior to 16-14 tya likely relied on other species of yeast (not Saccharomyces).

Each ancient human culture that relied upon yeasts and other microbes for fermentation would have employed specific techniques for ensuring the presence of those microbes. For this review, we will focus primarily on Western bread. Evidence for the simplest method for baking leavened bread derives from an Old Kingdom tomb dating to between 2450 and 2401 BCE (Moussa et al., 1977, p. 153; Samuel, 1989). It involves mixing and kneading the dough in a bowl and baking directly on the fire's hot ashes, and was likely used by peasants and workers in later eras (Samuel, 1989). During all of the Kingdoms, molds were also used, with the dough either being poured into the mold, or in later periods, shaped (Samuel, 1989; Baking Ancient Egyptian Bread, 2018). Other sources propose a pre-fermented mix prepared by roasting malt loaves, crushing them, mixing them with water and whole grains (likely the yeast source) and allowing it to ferment before straining it through a straw mat, although the precise time period method was used remains unclear (Frey, 1930). The dough was kneaded by walking on it, like one might press grapes, baking the loaves in large ovens lined with bricks, stone slabs, or in rare cases, iron depending on the era (Frey, 1930).

Frey (1930) hypothesizes that knowledge of these fermentation and baking methods passed from Egypt and Babylon to ancient Greece and ancient Jewish cultures (Frey, 1930). From Greece, the knowledge passed to Rome, where they kneaded dough by hand instead of by foot (Frey, 1930). Pliny the Elder records that professional bakers did not appear in Rome until 168 BCE, after a war with King Perseus (Pliny the Elder; Frey, 1930). However, reality was undoubtedly more complex, whether with regard to the spread of bread-making, the grains used in bread-making (Verberg, 2019) or the techniques for sharing and managing yeasts and starters. The intensive study of historic, pre-historic and ethnographic records relating to the care of yeasts and starters would be very rewarding. The spread of fermented beverages such as wine and beer, which were linked to bread making through the sharing of yeasts between brewers and bakers, is better studied (Frey, 1930; 
Sicard and Legras, 2011). Because devices and vessels were often used to store yeasts from beer to later (even months later) make bread (Verberg, 2019), it is possible that ancient yeast proteins, genomes, and maybe even living cells, may be recoverable (and would prove a rich data source for comparative analysis). However, the burden of proof to document that the yeasts that have been discovered are truly ancient is (and should be) very high.

The first "commercial" production of yeast, that is the growing of yeast for the sole purpose of selling it to others, arose in the 1700 s, but unlike modern pure culture production, it was more the art of keeping a continuous colony of fermenting yeast in dough or hops for use in brewing more than baking (Frey, 1930). Prior to the introduction of these "commercial" yeasts, the primary yeast source for bakers and housewives was the yeasty foam or dreg waste collected from completed beer fermentations, and were sold directly by breweries (Frey, 1930). In the 1780s and 1790s, the development of compressed yeast began to appear in England, Germany, and Netherlands (Frey, 1930). Early recipes for commercial pressed yeasts consisted of a pressed block of fermented hops, rye, and malt, or some mixture of the three depending on the country and local producer, and could contain as little as $4-6 \%$ yeast, which would consist of multiple strains as well as any associated bacteria (Frey, 1930). By the early 1800s, these compressed yeasts were outcompeting the excess or spent yeast from brewers. In addition to compressed yeast, records from 1771 provide a simple drying method for yeast, which required mixing yeast and wood ash together before placing it in the sun to dry further (Frey, 1930). Dried yeast was first sold commercially in Vienna in 1822. Other yeast preservation methods besides drying included bottling yeast, covering the yeast with oil, and burying it several feet underground to keep it cool (Frey, 1930).

The word "yeast" was not linked to fermentation until 1859. J. H. van den Broek, working in Utrecht, Netherlands, identified vegetative cells that existed and replicated in fermenting media, which he dubbed yeast (Frey, 1930; Barnett, 2000). The word yeast derives from Late Old English gist, a cognate to the Middle German words gest, meaning dregs or dirt, and jest, meaning foam, as well as the Old High German word gesan/jesan, meaning to ferment (Barnhart, 1995). All of these cognates refer to where yeast could be found and, to some extent, the manifestations of its presence (the foam). Louis Pasteur hypothesized that yeast could be purified using tartaric acid, which he hypothesized would kill unwanted bacteria and yeast, and recommended using pure cultures for fermentation (Frey, 1930; Gélinas, 2010). The tartaric acid method, however, only removed bacteria from yeast mixtures, but did not prevent wild spoilage yeasts from replicating (Frey, 1930). Emil Christian Hansen, director of the Carlsberg Laboratory in Copenhagen, took up the work of purifying yeast strains based on the work of Pasteur and the 1870 work of Oscar Brefeld, who proposed pure cultures could be derived from single cells (Ling, 1909; Frey, 1930). While Hansen succeeded in 1879 , later publishing his work in 1883, few accepted purified strains under the belief that purified strains could not remain pure, and that the taste would worsen in the absence of the products (what we would now call metabolites) of the bacteria that had been removed (Ling, 1909; Frey, 1930). It would take 20 years before pure cultures became common. The impure "yeast" used before Hansen typically contained multiple strains of yeast, as well as a variety of species of bacteria (Frey, 1930).

In the mid to late 1800 s bakers began to value "pure" cultures (Frey, 1930). It was in this context that John C. Pennington patented a method, in 1879 , that used a microscope to check if the yeast was a pure culture without bacterial contamination (Gélinas, 2010). The first known patent that followed Pasteur's insistence on sterility of both media and equipment was in 1891, by Alfred Jörgensen, director of his own lab by the same name, and Axel Bergh, directory of his own lab in Stockholm, Sweden and owner of several breweries (Gélinas, 2010; Grönberg, 2019). Their patent used a sterile aeration system, thus maintaining strain purity and enhancing growth (Gélinas, 2010). Sterile media and equipment are required to maintain pure cultures, and are now standard in modern yeast production. By the early 1900s, better aeration methods and the invention of centrifuges (which replaced filters) increased production capability (Frey, 1930). This, in turn, allowed the expansion of the commercial baking industry, and by the 1920 s commercial yeast as we know it was born (Frey, 1930; Gélinas, 2010).

While our main focus in this review is on Western bread, we note that Asian and African breads have a rich history; the future study of which will undoubtedly enrich our understanding of yeast history, ecology and evolution. In China, fermented sourdough bread has been an important diet item for at least the past 2000 years (Liu et al., 2018). Steamed sourdough bread is currently the most popular traditional fermented wheat product, accounting for $40 \%$ of consumed wheat in China, and is a popular breakfast item (Kim et al., 2009; Li et al., 2015; Liu et al., 2018). India has a variety of leavened and unleavened flatbreads (Mir et al., 2014). The oldest evidence of bread as of writing dates are the charred remains of flatbread dating back to 14,400 BCE from the Shubayqa1 dig site in northeastern Jordan (ArranzOtaegui et al., 2018); whether this bread was partially leavened is, as of yet, unclear.

\section{SIGNATURES OF DOMESTICATION IN SACCHAROMYCES CEREVISIAE BAKING STRAINS}

Until quite recently, large-scale genomic studies of baking strains have been non-existent, and more work is still needed to tie together the history of bread with the genetic history of these strains. This gap in knowledge is beginning to be rectified, with new phylogenetic analyses of commercial and sourdough baking strains illuminating a polyphyletic origin of baking strains (Peter et al., 2018; Bigey et al., 2020). Bakery strains surveyed thus far are largely from European isolates, and fall into two major clades, suggesting at least two domestication events leading to commercial baking strains and sourdough baking strains, respectively (Bigey et al., 2020). Within these two clades, both noted for their mixed origins, the bakery strains are interspersed with strains isolated from many sources including wine, sake, clinical, and natural environments. Despite the intertwined history of beer and breadmaking, the phylogenetic relationships of beer and bread strains are largely separated. There are a few 
exceptions, including African maize dough strains clustering with African beer strains, and a subset of beer strains clustering with mixed origin bakery strains (Bigey et al., 2020). Surprisingly, no sequenced bakery strains cluster with Ale beer strains, although there is evidence of Ale beer strain introgression in some of the bakery strains (Bigey et al., 2020).

There are systematic differences between strains used in baking, strains associated with other fermentations, and strains not associated with human environments. This is true even though baking strains are not monophyletic, suggesting convergent adaptation to the dough fermentation environment. Baking strains tend to have more complex genetic architecture compared to laboratory strains (Steensels et al., 2014a), and fewer genes are differentially expressed in baking strains compared to domesticated wine and beer strains during dough fermentation (Aslankoohi et al., 2013). Commercial baking strains tend to be a higher ploidy (up to $68 \%$ of baking strains have a ploidy above $2 \mathrm{n}$ ) and have higher rates of aneuploidy (up to $17 \%$ of baking strains are aneuploid) than wild and semi-wild sourdough strains (up to 35\% are polyploid or aneuploid) (Bigey et al., 2020). Tetraploidization appears to have occurred at least once in the domestication of commercial baking strains, and translates to a significantly faster start of fermentation compared to diploid strains (Bigey et al., 2020). This trait was perhaps selected upon by bakers, giving rise to the numerous commercial baking strains with tetraploidy.

Polyploidy and aneuploidy are common signatures across all industrial S. cerevisiae (whether associated with bread, beer, or other fermentation environments). A higher ploidy leads strains to have lower sporulation efficiency, lower spore viability, and unstable mating types, especially compared to laboratory strains which are selected for easy and rapid reproduction (Liti et al., 2009; Borneman et al., 2011; Warringer et al., 2011; Steensels et al., 2014a). The side effects caused by higher ploidy complicate efforts to use traditional breeding and genetic modification techniques for strain improvement, which we discuss in more detail in the Bioengineering section, below. Thus, while higher ploidy appears to be beneficial for strain adaptation to the baking environment, it also hinders further strain improvement by limiting the types of techniques that can be used.

The ultimate signature of the evolution of bread yeasts is whether bakery strains display better dough fermentation performance (where "performance" can be defined in nearly as many ways as there are bakers) than do non-bakery strains. Common metrics to analyze dough fermentation performance include a variety of measurements related to carbon dioxide $\left(\mathrm{CO}_{2}\right)$ production, cell growth during fermentation, and dough height, as well as metrics related to human safety, consumption, and distribution, such as lack of biogenic amine production, volatile organic compounds, bread texture, and freeze/thaw tolerance (De Vuyst and Neysens, 2005; Aslankoohi et al., 2016) and, of course, tastes, flavors and aromas (and the features associated with them).

There are general indicators of domestication shared amongst industrial strains used in bioethanol, bread, beer, and wine (Spor et al., 2009; Sicard and Legras, 2011; Randez-Gil et al., 2013). Intriguingly, many industrial strains from non-bakery origins can achieve similar $\mathrm{CO}_{2}$ production during dough fermentation compared to bakery strains (Aslankoohi et al., 2013). The simplest explanation for this observation is that there is a tradeoff between $\mathrm{CO}_{2}$ production and other bread fermentation traits. For example, attempts to increase $\mathrm{CO}_{2}$ production by manipulating expression of metabolic enzymes have generally failed, as increases in $\mathrm{CO}_{2}$ come at the cost of traits like decreased growth yield (Schaaff et al., 1989; Navas et al., 1993). This might translate to longer fermentation times and smaller loaves, and have a detrimental effect as yeast provide nutrition and flavor (Olsson and Nielsen, 2000; Bekatorou et al., 2006; Birch et al., 2013a,b).

The most convincing evidence to date of bread-specific domestication comes from a survey by Bigey et al., of a collection of sourdough strains, commercial bakery strains and non-bakery strains of diverse origins and genetic groups. They show that sourdough and commercial baking strains produce significantly more $\mathrm{CO}_{2}$, both in rate and in total, compared to non-bakery strains. Sourdough and commercial baking strains also had a shorter lag time than non-bakery strains, meaning they started fermenting and raising the dough earlier than did non-bakery strains (Bigey et al., 2020). This study also identified differences between sourdough strains and commercial bakery strains. Commercial strains achieved a faster fermentation onset than did sourdough strains, but sourdough ultimately achieved higher population sizes. Overall, these results support the hypothesis that commercial baking strains and at least some sourdough strains (bearing in mind that there may be a lot of strain diversity in starters) were domesticated and are better adapted to their environment than other strains.

\section{IMPORTANT TRAITS AND ASSOCIATED GENES FOR BREAD BAKING}

In this next section, we explore the particular environmental pressures that $S$. cerevisiae must handle during dough fermentation, and the desirable characteristics for optimizing $S$. cerevisiae baking strains. We address maltose utilization and glucose repression; osmotic stress; glycerol, trehalose, and proline accumulation; and aromatic compound production (Table 1).

\section{Maltose Utilization and Glucose Suppression in Bread Dough}

The fermentation process that results in dough rising relies on $S$. cerevisiae consuming sugar and producing ethanol and $\mathrm{CO}_{2}$. $S$. cerevisiae prefers easily fermentable monosaccharides such as glucose and fructose, however, many bread doughs have a very low sugar content (with the exception of high sugar doughs). As a result, the $S$. cerevisiae in dough must use more complex sugars such as maltose. Maltose is a disaccharide composed of two glucose molecules joined by an $\alpha(1 \rightarrow 4)$ bond, obtained by the breakdown of starch by amylase enzymes naturally found in grains. The ability to ferment maltose is variable across species and strains of yeast (Bell et al., 2001; Houghton-Larsen and Brandt, 2006; Naumova et al., 2013), with commercial baking 


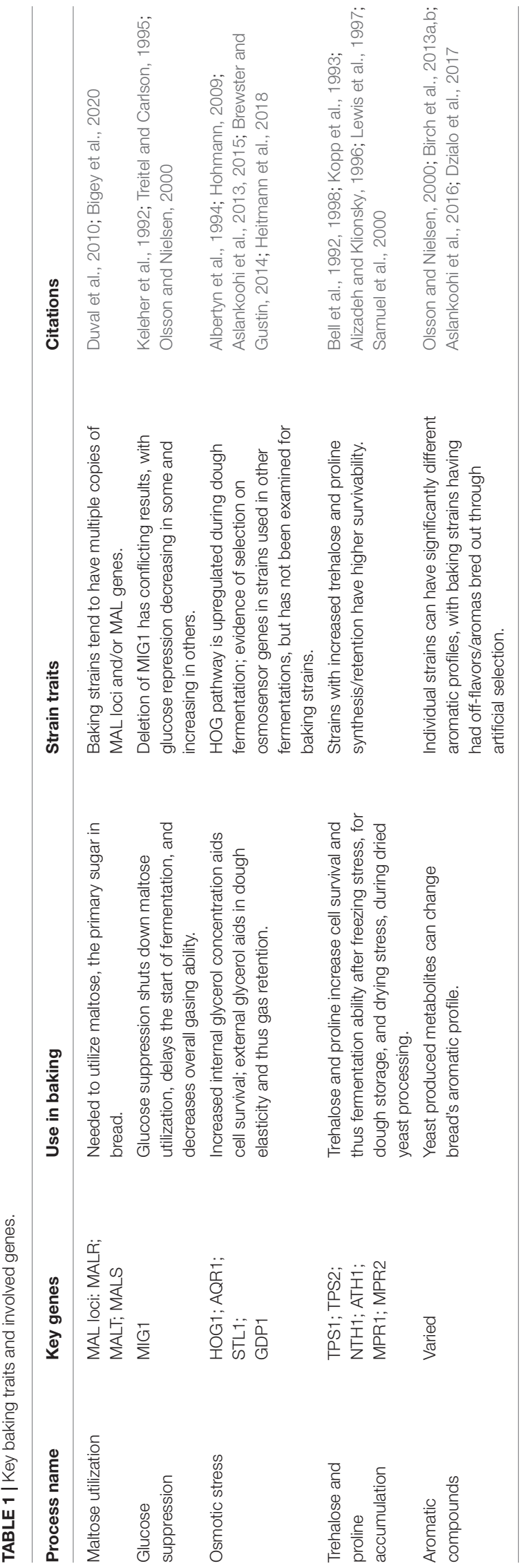

strains more adapted to maltose utilization than are non-bakery strains (Bell et al., 2001).

Maltose use is conferred by one or more functional MAL loci. There are five unlinked, subtelomeric MAL loci (MAL1MAL4, MAL6) in S. cerevisiae. Each MAL locus includes the genes MALR, which encodes a transcriptional regulatory protein, MALT, which encodes maltose permease, and MALS, which encodes maltase (Naumov et al., 1994; Olsson and Nielsen, 2000; Houghton-Larsen and Brandt, 2006). MAL1 on chromosome VII is likely the ancestral locus from which other MAL loci are derived, as all examined $S$. cerevisiae strains and its closest relative Saccharomyces paradoxus have MAL1 at this position (Duval et al., 2010). While MAL loci generally exhibit high sequence and functional similarity, there are several different maltose utilization phenotypes that have been described (Duval et al., 2010). Some MAL alleles may even be non-functional, for example, the lab strain S288C has two MAL loci (MAL1 and MAL3), but cannot ferment maltose due to non-functional MALR genes (Day et al., 2002a,b). The extent of allelic variation of MAL loci and resulting phenotypes could be revisited in light of new collection and sequencing efforts.

In the S. cerevisiae pangenome, the presence of MAL loci is variable across strains, with particular MAL genes found in most of the 1011 genomes surveyed, and some MAL genes only present in about half (Peter et al., 2018). Increased copy number of specific MAL genes appears to be a common adaptation to beer and bread environments (Figure 1; Duval et al., 2010; Bigey et al., 2020). Higher copy number of genes associated with other enzymes involved in isomaltose and sucrose utilization are also reported (Bell et al., 2001; Bigey et al., 2020). To our knowledge, no specific tests have been performed to assess the effect of increased copy number of MAL loci on dough fermentation performance. However, results from experimental evolution support the conclusion that increased copy number of nutrient transporters confers a fitness advantage in nutrient limited environments (Dunham et al., 2002; Gresham et al., 2008; Payen et al., 2014; Selmecki et al., 2015; Sunshine et al., 2015; Smukowski Heil et al., 2017). One could speculate that increases in MAL copy number could provide an advantage during fermentation, possibly increasing the speed of fermentation, or shortening the onset of fermentation, though more research is required to pinpoint the possible advantages.

In addition to the presence and copy number of MAL loci, efficient maltose utilization is heavily impacted by a regulatory system known as glucose repression. In the presence of monosaccharides, S. cerevisiae activates the glucose repression pathway, which shuts down aerobic respiration in favor of anaerobic fermentation (Sicard and Legras, 2011), yielding alcohol in place of $\mathrm{CO}_{2}$. This can be problematic in bread baking, as glucose repression will also shut down fermentation of maltose and other di- and polysaccharides. This creates a lag time, which delays the start of fermentation and decreases overall gasing ability. The duration of lag time depends on both expression and production of alternate carbon metabolizing proteins such as maltose and MAL genes, as well as how quickly yeast cells can lift glucose repression and activate respiration (Cerulus et al., 2018; Perez-Samper et al., 2018; Vermeersch et al., 2019). During this 


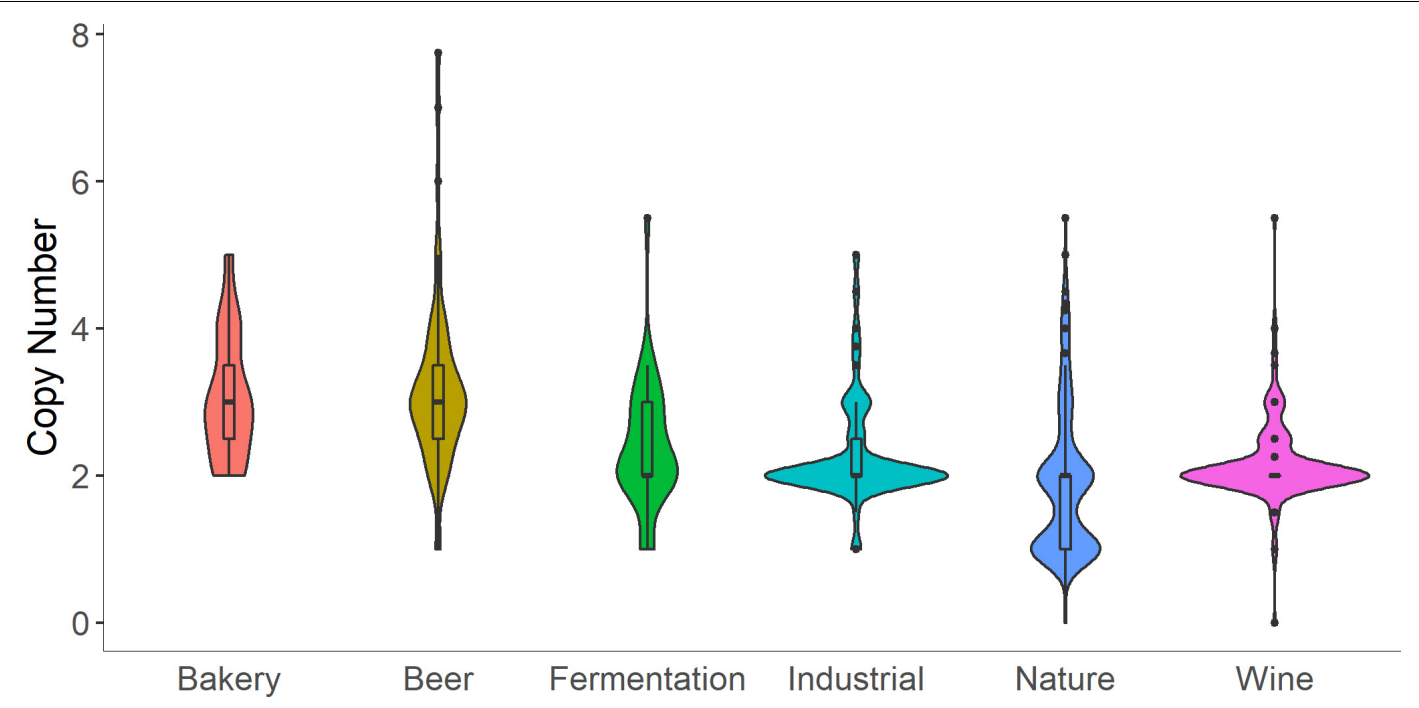

FIGURE 1 | Copy number of the maltase gene, MAL12, is increased in bakery strains. Copy number and ecological origin data were collected from Peter et al. (2018). Here, "Fermentation" refers to fermentation separate from beer, wine, and bread, and includes isolates from processes like cacao fermentation. "Industrial" refers to processes separate from fermentation, and includes isolates from origins like bioethanol production. "Nature" refers to isolates from trees, fruit, flowers, soil, etc.

time the dough does not rise, pausing the bread baking process until the glucose is depleted and the yeast are able to switch to maltose as their main substrate. This can translate to a smaller finished loaf than a dough made using a strain with combined glucose and maltose fermentation (Olsson and Nielsen, 2000).

Glucose repression in bread dough functions through the suppression of MAL loci by the regulatory protein Mig1 (Keleher et al., 1992; Treitel and Carlson, 1995). Mig1 recognizes and binds the MAL promoters, recruiting Ssn6 and Tup1 to inhibit gene expression (Keleher et al., 1992; Treitel and Carlson, 1995). Mig1 is therefore a potential target to increase the speed and efficiency of maltose utilization in the presence of glucose, and thus the fermentation process as a whole. However, gene knockouts have shown that deletion of both MIG1 and MIG2 does not increase maltose use in bread, and in some strains, MIG1 deletion actually increases glucose repression, indicating there are other regulating factors involved (Olsson and Nielsen, 2000). For example, deletion of MIG1 in an industrial strain increased the effects of glucose repression on maltose, but did not enhance repression in the laboratory strain (Olsson and Nielsen, 2000). Furthermore, the MIG1 deletion negatively affected the industrial strain's growth rate, but did not hinder growth in the laboratory strain (Olsson and Nielsen, 2000). The non-uniform deletion response, especially between laboratory and industrial strains, indicates that there are important genetic background effects. When MAL loci are placed under constitutive promoters independent of Mig1, maltose and glucose metabolism cooccur, lowering fermentation time and increasing gassing power (Olsson and Nielsen, 2000).

With maltose utilization being a vital part of bread fermentation, continued research into methods that enhance maltose utilization are necessary. Areas that require attention include functional differences between MAL loci, the effect of copy number variation on fermentation dynamics, and strain optimization to allow co-metabolism of glucose and maltose. Better understanding of these characteristics could lead to shorter fermentation times, and increased bread volume for industrial producers.

\section{Managing Osmotic Stress via Glycerol Accumulation and the HOG Pathway}

Saccharomyces cerevisiae experiences extreme osmotic shock during dough fermentation and commercial yeast processing (Aslankoohi et al., 2013, 2015; Randez-Gil et al., 2013). The semisolid state of dough and high salt and/or high sugar recipes create hyperosmotic and ionic stress (Hernández-López et al., 2003; Aslankoohi et al., 2013; Randez-Gil et al., 2013). In the face of hyperosmotic conditions, cells lose water due to the osmotic gradient formed between both sides of the cell membrane, and growth is halted (Hohmann et al., 2007). This can result in decreased viability and decreased fermentation capacity, which manifests in longer proofing times and smaller loaves. Thus, managing osmotic stress is a fundamental property of strains used in bread baking.

Saccharomyces cerevisiae responds to osmotic stress through strong upregulation of $A Q R 1$, a membrane transporter for amino acid excretion during restrictive growth conditions (Aslankoohi et al., 2013), and through the production and accumulation of glycerol. Glycerol prevents water loss by balancing intracellular osmolarity so it more resembles the environment (Sasano et al., 2012b; Aslankoohi et al., 2013, 2015). Glycerol homeostasis is managed through the high-osmolarity glycerol (HOG) pathway, a mitogen-activated protein kinase (MAPK) pathway central in stress-activated response and signaling (Hohmann, 2009; Brewster and Gustin, 2014). The HOG pathway is well conserved, 
with the central player HOG1 homologous to mammalian MAPK p38, which is involved in inflammatory and stress responses (Han et al., 1994; Raingeaud et al., 1995). Individual genes within the HOG pathway exhibit different evolutionary rates between or within lineages of fungi, with osmosensory genes upstream of HOG1 evolving more rapidly (Nikolaou et al., 2009; Wu et al., 2010; Li et al., 2013). For example, the osmosensing transmembrane receptors MBS2 and SLN1 have high nucleotide diversity, and a branch-site model test to detect selection acting on two Chinese rice wine strain branches is suggestive of adaptation to osmotic stress caused by high sugar in rice wine (Li et al., 2013). In contrast, there is some evidence that osmotic adaptation to high sugar dough is not a defining feature of bakery strains, and instead, osmotolerance is variable across both commercial baking strains and non-bakery strains (Bell et al., 2001). Whether the bakery strains that can ferment in high sugar dough do so as a result of selection on osmo-receptors has not yet been examined.

The HOG pathway response to osmotic shock is transitory, with the cell strongly suppressing HOG1 once the cell stabilizes (Hernández-López et al., 2003; Hohmann et al., 2007). How fast strains can respond to osmotic stress, and whether the response is maintained or not, may impact dough fermentation dynamics. One study found that baking strains of another yeast, Torulaspora delbrueckii, responded faster to osmotic stress, with a faster increase in glycerol levels, out performing two commercial S. cerevisiae baking strains in high sugar doughs (HernándezLópez et al., 2003). The T. delbrueckii strains also decreased glycerol concentrations after the initial inoculation, whereas the $S$. cerevisiae strains maintained high glycerol concentrations throughout fermentation. This may represent another trait that could be further optimized in S. cerevisiae baking strains.

Genes involved in glycerol homeostasis are some of the most differentially upregulated genes during the onset of dough fermentation and are essential for yeast growth in dough (Aslankoohi et al., 2013). When cells encounter osmotic stress, HOG1 induces expression of the glycerol pathway genes GPD1, $G P P 1$, and GPP2. GPD1, the first enzyme in the synthesis pathway of glycerol, is key in glycerol content and successful dough fermentation (Albertyn et al., 1994). Strains and species with different glycerol production levels often show differences in expression of GPD1 and/or Gpd1 enzymatic activity (Attfield and Kletsas, 2000; Oliveira et al., 2014), although this has not been systematically surveyed in diverse baking strains. GPD1 has thus been a target for genetic manipulation to modulate glycerol accumulation. Deletion of GPD1 results in decreased glycerol concentration, reduced $\mathrm{CO}_{2}$ production, and delays in dough fermentation (Aslankoohi et al., 2013, 2015). Overexpression of GPD1, on the other hand, can increase fermentation rates in high-sugar dough and improve dough gas retention, although improvements are more stark for laboratory strain backgrounds than bakery strain backgrounds (Barrett et al., 2000; Baik and Chinachoti, 2002; Styger et al., 2011; Aslankoohi et al., 2015; Heitmann et al., 2018). This is suggestive that some baking strains are indeed better adapted to dough conditions, and produce dough with better gas retention, due to higher base levels of glycerol amongst other selected traits.
The glycerol proton symporter STL1 is also significantly upregulated upon the start of dough fermentation. STL1 is part of a glycerol uptake system that imports glycerol from the environment to increase internal glycerol concentrations (Ferreira et al., 2005; Hohmann et al., 2007; Duskova et al., 2015). Stl1 functions together with the glycerol export protein Fps1 to control intracellular glycerol content and modulate glycerol leakage into the dough (Oliveira et al., 2003; Thorsen et al., 2006; Hohmann et al., 2007; Hohmann, 2009; Randez-Gil et al., 2013). Some glycerol leakage is beneficial, as it softens and relaxes the dough, increasing its ability to contain $\mathrm{CO}_{2}$ and thus increasing overall dough rise (Aslankoohi et al., 2015). However, excessive glycerol in dough can have a negative effect on bread aroma and taste (Olsson and Nielsen, 2000). Glycerol levels also affect the shelf-life of finished loaves (Barrett et al., 2000; Baik and Chinachoti, 2002; Styger et al., 2011; Heitmann et al., 2018).

\section{Trehalose and Proline Accumulation Protect Against Osmotic, Freeze, and Desiccation Stress}

In addition to osmotic stress, baking yeast are subject to a variety of other stressors, particularly related to industrial manufacturing and distribution processes. For example, frozen dough is used to provide easier access to fresh-baked bread for consumers while balancing labor conditions for bakers and allowing for greater geographic distribution of products (Hsu et al., 1979; Luo et al., 2018). Typical baking strains fail to retain leavening ability following freezing, and thus cryotolerant strains have been isolated from natural environments, or developed through genetic modifications in the lab (Hino et al., 1987; Hahn and Kawai, 1990; Matsutani et al., 1990; Nakagawa and Ouchi, 1994; Takagi et al., 1997; Shima et al., 1999). Much of the attention in freeze tolerant baking strains has focused on the naturally occurring cryoprotectants trehalose and proline, which protect cells from a variety of stresses including osmotic stress, freezing, dehydration, and heat shock (Shima et al., 1999; Sasano et al., 2012a). Trehalose and proline accumulation allow commercial baking yeast to survive processing and distribution either in dehydrated, dry yeast or frozen in pre-made dough (Sasano et al., 2010, 2012b; Randez-Gil et al., 2013). We address current knowledge of trehalose and proline accumulation in dough in turn, below.

Trehalose is a sugar composed of two glucose molecules linked at their 1-carbons. The cellular concentration of trehalose is balanced by the relative rates of its synthesis and degradation. Trehalose-6-phosphate synthetase (TPS1) and trehalose-6-phosphate phosphatase (TPS2) synthesize trehalose in the cytoplasm (Bell et al., 1992, 1998), while neutral trehalase $(N T H 1)$ and acid trehalase $(A T H 1)$ breakdown trehalose (Kopp et al., 1993; Alizadeh and Klionsky, 1996). High levels of trehalose are strongly correlated with high levels of stress tolerance (Attfield, 1997), however, the trehalose content in commercial baking strains varies considerably (Lewis et al., 1997). Deletion of one or both NTH1 and ATH1 increases trehalose concentrations and gassing power of frozen doughs, with the NTH1 deletion providing the most freeze protection. This has made NTH1 a 
common target for creation of freeze-tolerant baking strains (Shima et al., 1999; Dong et al., 2016; Xi et al., 2016; Takagi, 2017). Deletion of one, but not both NTH1 and ATH1 also increased the yeast's tolerance of dry conditions (Kim et al., 1996; Shima et al., 1999).

The amino acid proline functions in stress response across many organisms (Csonka and Hanson, 1991; Delauney and Verma, 1993). Proline stabilizes proteins and membranes, lowers the $\mathrm{T}_{m}$ of DNA, and scavenges reactive oxygen species (ROS), which is believed to be a main killer of yeast in osmotic, drying, and freezing stress (Samuel et al., 2000; Takagi, 2008; Sasano et al., 2010, 2012b). However, proline is not naturally elevated in response to these stressors in S. cerevisiae, and instead appears to be constitutively expressed (Brandriss and Falvey, 1992; Samuel et al., 2000; Kaino and Takagi, 2008; Takagi, 2008; Sasano et al., 2010, 2012a,b; Randez-Gil et al., 2013). Nevertheless, researchers have demonstrated that synthetically increasing $S$. cerevisiae intracellular proline levels by making genetic modifications to the proline synthesis and breakdown pathways confers higher freezing and desiccation tolerance, and better fermentation performance in frozen and sweet doughs (Nomura and Takagi, 2004; Sekine et al., 2007; Sasano et al., 2012a,b; Randez-Gil et al., 2013; Steensels et al., 2014b; Tsolmonbaatar et al., 2016). Other efforts have shown that different alleles of the genes MPR1 and MPR2, which detoxify the toxic proline analog azetidine2-carboxylate, also are involved in proline accumulation and mitigating desiccation stress and cryotolerance (Nomura and Takagi, 2004; Sasano et al., 2010).

Intriguingly, efforts to simultaneously increase levels of both trehalose and proline have yielded higher tolerance to oxidative and freezing stresses and improved the fermentation ability in dough after being frozen compared with the singular accumulation of proline or trehalose (Sasano et al., 2012a). This work suggests that proline and trehalose protect yeast cells from short-term and long-term freezing effects, respectively, and is an interesting area for further pursuit which could be beneficial to the frozen dough industry.

\section{Aromatic Compound Production}

The sensory qualities of bread, such as aroma and taste, are essential metrics of quality for consumers, and are strongly influenced by volatiles and secondary metabolites produced by yeast (Schieberle and Grosch, 1991; Frasse et al., 1993; Olsson and Nielsen, 2000; Birch et al., 2013a,b; Pico et al., 2015; Aslankoohi et al., 2016; Dzialo et al., 2017) The identity and relative abundance of aroma compounds vary widely among strains of $S$. cerevisiae, and, more broadly, across species of yeasts (Christiaens et al., 2014; Steensels et al., 2014b). Variation in aromas may relate to the adaptive diversification of yeast strains and species in as much aroma compounds play important physiological and ecological roles in yeasts, including regulation of growth, communication, and signaling to insect vectors (Richard et al., 1996; Bruce et al., 2004; Leroy et al., 2011; Becher et al., 2012; Davis et al., 2013). The attraction of insect vectors has been shown to mediate important yeast life history traits including outcrossing and dispersal (Reuter et al., 2007; Christiaens et al., 2014; Stefanini et al., 2016; Madden et al., 2018).
As a result, non-human animals may be important in engendering the diversity and abundance of aromas produced among yeast strains. Recent studies support the hypothesis that domestication of $S$. cerevisiae, by humans, for various industrial applications has favored desirable aroma compounds, and disfavored off-flavors in bread and other fermented food (Wedral et al., 2010; Suárez-Lepe and Morata, 2012; Gallone et al., 2016; Padilla et al., 2016; Fay et al., 2019; Langdon et al., 2019).

Different sourdough and commercially available baking strains of $S$. cerevisiae can generate significantly different aroma profiles in bread (Birch et al., 2013a; Pétel et al., 2017). The more influential aroma compounds include alcohols, aldehydes, ketones (e.g., acetoin and diacetyl), and esters (e.g., ethyl acetate), which are in part regulated via the Ehrlich metabolic pathway (Styger et al., 2011; Birch et al., 2013a; Pétel et al., 2017). Typically, ethyl acetate has an aroma similar to pineapple, diacetyl and acetoin are buttery, alcohols and aldehydes provide floral and sometimes fruit notes, and esters, particularly saturated esters, are fruity in nature (Fingolfn Practically Science, 2013). Combined, these molecules provide the aromatic qualities of each loaf, and can be quantified and analyzed to detect variation across strains. One such study assessed aromas produced by seven different $S$. cerevisiae bakery strains and found that aroma compounds varied by an order of magnitude between strains for compounds like 3-methylbutanal, which has a malty aroma, and 2,3-butanedione, which has a buttery aroma. While not all compounds had such ranges, the variety of aroma concentration would provide each bread with a unique aroma profile, or lack thereof (Aslankoohi et al., 2016; Reese et al., 2020). This is compounded by the fact that different compounds have different odor detection thresholds (ODT), or the concentration at which the human nose can detect it in water. The range of aroma compounds and their concentration could overlap with the compounds' ODT. Indeed, one strain was found to have significantly less of almost all aroma compounds tested, meaning the bread would have less distinct scent compared to bread prepared with one of the other commercial baking yeasts, as it would only have aromas from the flour and maillard reaction from the baking process.

Improving flavor and aroma in baked products is an active area of research, and includes a variety of techniques including experimental evolution, gene modifications and exploiting natural diversity (Dzialo et al., 2017), which we address in more depth below.

\section{FUTURE NEEDS}

Current commercial baking strains are not optimized for all desired baking and processing traits, as industry often uses strains due to historical reasons (Steensels et al., 2014a). Some common categories where additional optimization is needed include: increased fermentation capacity in sweet doughs, resistance to salt toxicity, better storage survival (frozen and dried), enhanced sensory qualities such as taste, aroma, and texture, synthesis of beneficial and functional metabolites such as antioxidants, phenols, xanthophyll, and anthocyanins, and microbial stability 
(Becker et al., 2003; Hernández-López et al., 2003; Wang et al., 2011; Steensels et al., 2014a; Palla et al., 2020). A strain that is capable of fermenting both standard lean dough and sweet doughs is also highly desirable (Hernández-López et al., 2003). Past and current efforts to meet these demands are summarized here through efforts to exploit natural diversity (bioprospecting) and genetic modification of existing strains (bioengineering).

\section{Bioprospecting}

Bioprospecting generally describes the search for new strains or species with beneficial characteristics that could be leveraged in industry. Bioprospecting of S. cerevisiae holds considerable promise considering the species' genetic and phenotypic diversity, with documented variation in many baking traits, including maltose utilization, aroma compounds, trehalose content, glycerol content, and general stress tolerance (Steensels et al., 2014b). Potential sources for baking strain bioprospecting can be generally divided into wild and man-made environments. Bioprospecting has already been employed to identify freezetolerant strains for use in baking (Hahn and Kawai, 1990), and there are numerous known cryotolerant species of Saccharomyces (Salvadó et al., 2011; Sylvester et al., 2015), some of which have already been utilized in cold fermented wines, beers, and ciders. Insects represent another promising potential source for yeast bioprospecting in natural environments, with insectisolated yeasts already proving to be viable options in bioethanol production, beer, and other industrial uses (Urbina et al., 2013; Steensels and Verstrepen, 2014; Sheppard et al., 2015; Mohd Azhar et al., 2017; Madden et al., 2018). In addition to isolating environmental yeasts from living in similar habitats to industrial conditions, there is the potential to use "contaminating" strains (e.g., contaminants in wine and beer), or spontaneous inoculated strains (e.g., beer, bread, etc.) which have evolved to survive in the desired environment and have potentially beneficial phenotypes for industry (Steensels et al., 2014a). This could be especially relevant for the baking industry, as wild-yeast fermented breads like sourdough, injera, Indian flatbreads, and Chinese steamed bread are teeming with microbial diversity (Zhang et al., 2011; Li et al., 2016; Tamang et al., 2016; Liu et al., 2018; Tadesse et al., 2019; Koricha et al., 2020). The S. cerevisiae strain diversity in these homemade grain ferments is largely unknown, and what is known is predominantly from European and North American isolates. Sampling from worldwide wild-yeast fermented breads, with a focus to increase representation from Africa, Asia, and South America, should be a priority for finding desirable baking strains in the future.

\section{Bioengineering}

Bioprospecting and bioengineering should not be considered mutually exclusive, but generally, bioengineering takes a more direct method in creating strains with beneficial phenotypes. Here, we will also use this term to encompass traditional breeding techniques. Somewhat surprisingly, selective breeding has not been heavily employed for industrial yeast strain improvement, despite the genetic and phenotypic variation present (see reviews Steensels et al., 2014a; Cubillos, 2016). Certainly there are challenges to traditional crosses, industrial S. cerevisiae strains are more prone to polyploidy and aneuploidy, and thus have a much lower spore viability than lab strains. Large scale screening for desirable traits in bread baking also presents practical challenges, like the ability to phenotype many individual crosses for fermentative traits and aroma compounds.

Despite these obstacles, the genetic mapping of complex traits in $S$. cerevisiae utilizing wild, clinical, lab, and industrial strains has been hugely successful (Ehrenreich et al., 2009; Liti and Louis, 2012; Swinnen et al., 2012; Gutiérrez et al., 2013; Jara et al., 2014; Wilkening et al., 2014; Bloom et al., 2019; Fournier et al., 2019), and underscores the ability to utilize direct crosses with the potential for selective breeding. There have been a few efforts to cross in useful traits for production of beer (Nikulin et al., 2018) and biofuels (Benjaphokee et al., 2012), and the wine industry in particular has used crossing, with a particular emphasis on interspecific hybridization with other Saccharomyces species. Hybrid crosses have been utilized in the wine industry to impart new flavors/aromas (Bellon et al., 2011, 2013; Kanter et al., 2019) and freeze-tolerance (Kishimoto, 1994; Zambonelli et al., 1997; Sipiczki, 2008; Pérez-Través et al., 2012), although these hybrids are typically sterile. New genetic editing techniques that allow for the successful completion of meiosis in normally sterile hybrids (Bozdag et al., 2019) is a promising development for the future use of interspecific hybrids in industry.

Finally, genetic modifications through gene deletions, allele replacements, and the insertion of new genetic materials have been successfully used to create baking strains with better fermentation dynamics and stress tolerance. We have highlighted many studies in this review that have utilized genetic modifications to better understand how individual genes or pathways contribute to desirable and undesirable traits in bread baking. However, moving these modified strains from research labs to the bakery presents major hurdles. Industrial use of genetically engineered organisms in food is illegal or highly regulated in most countries (Steensels et al., 2014a), and requires a change in consumer opinion of genetically modified organisms (GMO). In this regard, other common techniques like mutagenesis and directed laboratory evolution may hold more applicable potential. These methods have been applied to wine (Bellon et al., 2018; Mangado et al., 2018), biofuel (Sato et al., 2016; Peris et al., 2017), and beer (Baker and Hittinger, 2019), and to increase stress tolerance (Tsolmonbaatar et al., 2016) and freeze-tolerance in baking strains (Aguilera et al., 2010). A future that exploits natural variation through bioprospecting, traditional crosses, and directed laboratory evolution may help meet both consumer and baker preferences.

\section{CONCLUSION AND OUTSTANDING QUESTIONS}

There are clear desires of bakers and consumers for more flavorful, nutritious breads, and bakers need strains that show increased osmotolerance, cryotolerance, and desiccation resistance without the loss of fermentation capacity. In this review, we have outlined the genetic and phenotypic diversity of $S$. cerevisiae baking strains. We note that many researchers have 
documented variation in traits important for baking, including maltose utilization, trehalose content, glycerol content, aroma compounds, freeze tolerance, osmotolerance, and fermentation metrics like total $\mathrm{CO}_{2}$. Most of these studies have only used a small handful of strains, which suggests we have only surveyed a portion of the phenotypic variation that may exist. With many more isolates being collected from home, artisanal, and commercial bakers, there is an opportunity to better understand the evolutionary history of baking strain domestication and molecular evolution and selection on gene variants; map genetic loci contributing to complex traits; and develop better baking strains. We conclude with the following outstanding questions that can serve as a guide for future research.

Outstanding Questions:

Why are interspecies hybrids repeatedly found in beer and wine, but not bread?

What is the genetic diversity and biogeography of S. cerevisiae strains used in sourdough starters in the home?

\section{REFERENCES}

Aguilera, J., Andreu, P., Randez-Gil, F., and Prieto, J. A. (2010). Adaptive evolution of baker's yeast in a dough-like environment enhances freeze and salinity tolerance. Microb. Biotechnol. 3, 210-221. doi: 10.1111/j.1751-7915.2009. 00136.x

Albertyn, J., Hohmann, S., Thevelein, J. M., and Prior, B. A. (1994). GPD1, which encodes glycerol-3-phosphate dehydrogenase, is essential for growth under osmotic stress in Saccharomyces cerevisiae, and its expression is regulated by the high-osmolarity glycerol response pathway. Mol. Cell. Biol. 14, 4135-4144. doi: $10.1128 / \mathrm{mcb} \cdot 14.6 .4135$

Alizadeh, P., and Klionsky, D. J. (1996). Purification and biochemical characterization of the ATH1 gene product, vacuolar acid trehalase, from Saccharomyces cerevisiae. FEBS Lett. 391, 273-278. doi: 10.1016/0014-5793(96) 00751-X

Arranz-Otaegui, A., Carretero, L. G., Ramsey, M. N., Fuller, D. Q., and Richter, T. (2018). Archaeobotanical evidence reveals the origins of bread 14,400 years ago in northeastern Jordan. Proc. Natl. Acad. Sci. U S A. 115, 7925-7930. doi: 10.1073/pnas.1801071115

Aslankoohi, E., Herrera-Malaver, B., Rezaei, M. N., Steensels, J., Courtin, C. M., and Verstrepen, K. J. (2016). Non-Conventional Yeast Strains Increase the Aroma Complexity of Bread. PLoS One. 11:10. doi: 10.1371/journal.pone.0165126

Aslankoohi, E., Rezaei, M. N., Vervoort, Y., Courtin, C. M., and Verstrepen, K. J. (2015). Glycerol Production by Fermenting Yeast Cells Is Essential for Optimal Bread Dough Fermentation. PLoS One. 10:3. doi: 10.1371/journal. pone. 0119364

Aslankoohi, E., Zhu, B., Rezaei, M. N., Voordeckers, K., De Maeyer, D., Marchal, K., et al. (2013). Dynamics of the Saccharomyces cerevisiae Transcriptome during Bread Dough Fermentation. Appl. Environ. Microbiol. 79, 7325-7333. doi: 10.1128/AEM.02649-13

Ball. Baking Ancient Egyption Bread (2018). At the Mummies' Ball. Baking Ancient Egyption Bread. Available online at: https://www.atthemummiesball. com/baking-ancient-egyptian-bread/. (accessed July 13, 2020).

Attfield, P. V. (1997). Stress tolerance: The key to effective strains of industrial baker's yeast. 15, 1351-1357. doi: 10.1038/nbt1297-1351

Attfield, P. V., and Kletsas, S. (2000). Hyperosmotic stress response by strains of bakers' yeasts in high sugar concentration medium. Lett. Appl. Microbiol. 31, 323-327. doi: 10.1046/j.1472-765x.2000.00825.x

Aviles, G. (2020). Faced with flour and yeast shortages, bakers get creative. Available online at: https://www.nbcnews.com/pop-culture/pop-culture-news/ faced-flour-yeast-shortages-bakers-get-creative-n1180171. (accessed June 30, 2020).
Are there molecular signatures of selection in baking strains?

Do signatures of domestication differ between fermented breads from different cultures?

\section{AUTHOR CONTRIBUTIONS}

$\mathrm{CL}$ and $\mathrm{CSH}$ were responsible for the writing and editing of this manuscript. RD and AM were responsible for the editing of this manuscript. All authors contributed to the article and approved the submitted version.

\section{FUNDING}

This work was supported in part by a North Carolina Biotechnology Center grant 2019-BIG-6513 to RD.

Baik, M.-Y., and Chinachoti, P. (2002). Effects of Glycerol and Moisture Redistribution on Mechanical Properties of White Bread. Cereal Chem. 79, 376-382. doi: 10.1094/CCHEM.2002.79.3.376

Baker, E. P., and Hittinger, C. T. (2019). Evolution of a novel chimeric maltotriose transporter in Saccharomyces eubayanus from parent proteins unable to perform this function. PLoS Genet. 15:4. doi: 10.1371/journal.pgen.100 7786

Barnett, J. A. (2000). A history of research on yeasts 2: Louis Pasteur and his contemporaries, 1850-1880. Yeast 16, 755-771.

Barnhart, R. (1995). "Yeast," in The Barnhart Concise Dictionary of Etymology: The Origins of American English Words, ed. R. Barnhart (New York, NY: W.H. Wilson Company), 894.

Barrett, A. H., Cardello, A. V., Mair, L., Maguire, P., Lesher, L. L., Richardson, M., et al. (2000). Textural Optimization of Shelf-Stable Bread: Effects of Glycerol Content and Dough-Forming Technique. Cereal Chem. 77, 69-176. doi: 10. 1094/CCHEM.2000.77.2.169

Becher, P. G., Flick, G., Rozpêdowska, E., Schmidt, A., Hagman, A., Lebreton, S., et al. (2012). Yeast, not fruit volatiles mediate Drosophila melanogaster attraction, oviposition and development. Funct. Ecol. 26, 822-828. doi: 10.1111/ j.1365-2435.2012.02006.x

Becker, J. V. W., Armstrong, G. O., van der Merwe, M., Lambrechts, M. G., Vivier, M. A., and Pretorius, I. S. (2003). FEMS Yeast Res. 4, 79-85. doi: 10.1016/S15671356(03)00157-0

Bekatorou, A., Psarianos, C., and Koutinas, A. A. (2006). Production of Food Grade Yeasts. Food Technol. Biotech. 44, 407-415.

Bell, P. J. L., Higgins, V. J., and Attfield, P. V. (2001). Comparison of fermentative capacities of industrial baking and wild-type yeasts of the species Saccharomyces cerevisiae in different sugar media. Lett. Appl. Microbiol. 32, 224-229. doi: 10.1046/j.1472-765X.2001.00894.x

Bell, W., Klaassen, P., Ohnacker, M., Boller, T., Herweijer, M., Schoppink, P., et al. (1992). Characterization of the 56-kDa subunit of yeast trehalose-6-phosphate synthase and cloning of its gene reveal its identity with the product of CIF1, a regulator of carbon catabolite inactivation. Eur. J. Biochem. 209, 951-959. doi: 10.1111/j.1432-1033.1992.tb17368.x

Bell, W., Sun, W., Hohmann, S., Wera, S., Reinders, A., De Virgilio, C., et al. (1998). Composition and Functional Analysis of the Saccharomyces cerevisiae Trehalose Synthase Complex. J. Biol. Chem. 273, 33311-33319. doi: 10.1074/jbc. 273.50.33311

Bellon, J. R., Eglinton, J. M., Siebert, T. E., Pollnitz, A. P., Rose, L., de Barros Lopes, M., et al. (2011). Newly generated interspecific wine yeast hybrids introduce flavour and aroma diversity to wines. Appl. Microbiol. Biotechnol. 91, 603-612. doi: 10.1007/s00253-011-3294-3 
Bellon, J. R., Ford, C. M., Borneman, A. R., and Chambers, P. J. (2018). A Novel Approach to Isolating Improved Industrial Interspecific Wine Yeasts Using Chromosomal Mutations as Potential Markers for Increased Fitness. Front. Microbiol. 9:1442 doi: 10.3389/fmicb.2018.01442

Bellon, J. R., Schmid, F., Capone, D. L., Dunn, B. L., and Chambers, P. J. (2013). Introducing a New Breed of Wine Yeast: Interspecific Hybridisation between a Commercial Saccharomyces cerevisiae Wine Yeast and Saccharomyces mikatae. PLoS One. 8:4. doi: 10.1371/journal.pone.0062053

Benjaphokee, S., Hasegawa, D., Yokota, D., Asvarak, T., Auesukaree, C., Sugiyama, et al. (2012). Highly efficient bioethanol production by a Saccharomyces cerevisiae strain with multiple stress tolerance to high temperature, acid and ethanol. N. Biotechnol. 29, 379-386. doi: 10.1016/j.nbt.2011.07.002

Bigey, F., Segond, D., Friedrich, A., Guezenec, S., Bourgais, A., Huyghe, L., et al. (2020). Evidence for two main domestication trajectories in Saccharomyces cerevisiae linked to distinct bread-making processes. Biorxiv [Preprint].

Birch, A. N., Petersen, M. A., Arneborg, N., and Hansen, ÅS. (2013a). Influence of commercial baker's yeasts on bread aroma profiles. Food Res. Int. 52, 160-166. doi: 10.1016/j.foodres.2013.03.011

Birch, A. N., Petersen, M. A., and Hansen, ÅS. (2013b). The aroma profile of wheat bread crumb influenced by yeast concentration and fermentation temperature. LWT Food Sci. Technol. 50, 480-488. doi: 10.1016/j.lwt.2012.08.019

Bloom, J. S., Boocock, J., Sebastian, T., Sadhu, M. J., Day, L., Oates-Barker, H., et al. (2019). Rare variants contribute disproportionately to quantitative trait variation in yeast. eLife 8:e49212 doi: 10.7554/eLife.49212

Borneman, A. R., Desany, B. A., Riches, D., Affourtit, J. P., Forgan, A. H., Pretorius, I. S., et al. (2011). Whole-Genome Comparison Reveals Novel Genetic Elements That Characterize the Genome of Industrial Strains of Saccharomyces cerevisiae. PLoS Genet. 7:2. doi: 10.1371/journal.pgen.1001287

Bozdag, G. O., Ono, J., Denton, J. A., Karakoc, E., Hunter, N., Leu, J.-Y., et al. (2019). Engineering recombination between diverged yeast species reveals genetic incompatibilities. Biorxiv [Preprint].

Brandriss, M. C., and Falvey, D. A. (1992). Proline biosynthesis in Saccharomyces cerevisiae: analysis of the PRO3 gene, which encodes delta 1-pyrroline-5carboxylate reductase. J. Bacteriol. 174, 3782-3788. doi: 10.1128/jb.174.11.37823788.1992

Brewster, J. L., and Gustin, M. C. (2014). Hog1: 20 years of discovery and impact. Sci. Signal. 7:343. doi: 10.1126/scisignal.2005458

Bruce, A., Verrall, S., Hackett, C. A., and Wheatley, R. E. (2004). Identification of volatile organic compounds (VOCs) from bacteria and yeast causing growth inhibition of sapstain fungi. Holzforschung. 58, 193-198. doi: 10.1515/HF. 2004.029

Carbonetto, B., Ramsayer, J., Nidelet, T., Legrand, J., and Sicard, D. (2018). Bakery yeasts, a new model for studies in ecology and evolution. Yeast 35, 591-603. doi: 10.1002/yea.3350

Cerulus, B., Jariani, A., Perez-Samper, G., Vermeersch, L., Pietsch, J. M. J., Crane, M. M., et al. (2018). Transition between fermentation and respiration determines history-dependent behavior in fluctuating carbon sources. eLife 7:e39234. doi: 10.7554/eLife.39234

Christiaens, J. F., Franco, L. M., Cools, T. L., De Meester, L., Michiels, J., Wenseleers, T., et al. (2014). The Fungal Aroma Gene ATF1 Promotes Dispersal of Yeast Cells through Insect Vectors. Cell Rep. 9, 425-432. doi: 10.1016/j.celrep. 2014.09.009

Csonka, L. N., and Hanson, A. D. (1991). Prokaryotic Osmoregulation: Genetics and Physiology. Annu. Rev. Microbiol. 45, 569-606. doi: 10.1146/annurev.mi. 45.100191.003033

Cubillos, F. A. (2016). Exploiting budding yeast natural variation for industrial processes. Curr. Genet. 62, 745-751. doi: 10.1007/s00294-016-0602-6

Davis, T. S., Crippen, T. L., Hofstetter, R. W., and Tomberlin, J. K. (2013). Microbial Volatile Emissions as Insect Semiochemicals. J. Chem. Ecol. 39, 840-859. doi: 10.1007/s10886-013-0306-Z

Day, R. E., Higgins, V. J., Rogers, P. J., and Dawes, I. W. (2002a). Characterization of the putative maltose transporters encoded by YDL247w and YJR160c. Yeast. 19, 1015-1027. doi: 10.1002/yea.894

Day, R. E., Rogers, P. J., Dawes, I. W., and Higgins, V. J. (2002b). Molecular analysis of maltotriose transport and utilization by Saccharomyces cerevisiae. Appl. Environ. Microbiol. 68, 5326-5335. doi: 10.1128/AEM.68.11.5326-5335.2002
De Vuyst, L., and Neysens, P. (2005). The sourdough microflora: biodiversity and metabolic interactions. Trends Food Sci. Technol. 16, 43-56. doi: 10.1016/j.tifs. 2004.02.012

De Vuyst, L., Henning, H., Van Kerrebroeck, S., and Leroy, F. (2016). Yeast diversity of sourdoughs and associated metabolic properties and functionalities. Int. J. Food Microbiol. 239, 26-34. doi: 10.1016/j.ijfoodmicro.2016. 07.018

De Vuyst, L., Van Kerrebroeck, S., Harth, H., Huys, G., Daniel, H.-M., and Weckx, S. (2014). Microbial ecology of sourdough fermentations: Diverse or uniform? Food Microbiol. 37, 11-29. doi: 10.1016/j.fm.2013.06.002

Delauney, A. J., and Verma, D. P. S. (1993). Proline biosynthesis and osmoregulation in plants. Plant J. 4, 215-223. doi: 10.1046/j.1365-313X.1993. 04020215.x

Dong, J., Chen, D., Wang, G., Zhang, C., Du, L., Liu, S., et al. (2016). Improving freeze-tolerance of baker's yeast through seamless gene deletion of NTH1 and PUT1. J. Ind. Microbiol. Biotechnol. 43, 817-828. doi: 10.1007/s10295-0161753-7

Duan, S.-F., Han, P.-J., Wang, Q.-M., Liu, W.-Q., Shi, J.-Y., Li, K., et al. (2018). The origin and adaptive evolution of domesticated populations of yeast from Far East Asia. Nat. Commun. 9:2690 doi: 10.1038/s41467-018-05106-7

Dunham, M. J., Badrane, H., Ferea, T., Adams, J., Brown, P. O., Rosenzweig, F., et al. (2002). Characteristic genome rearrangements in experimental evolution of Saccharomyces cerevisiae. Proc. Natl. Acad. Sci. U S A 99, 16144-16149. doi: 10.1073/pnas.242624799

Dunn, R. R., Amato, K. R., Archie, E. A., Arandjelovic, M., Crittenden, A. N., and Nichols, L. M. (2020). The Internal, External and Extended Microbiomes of Hominins. Front. Ecol. Evol. 8:2020 doi: 10.3389/fevo.2020.00025

Duskova, M., Borovikova, D., Herynkova, P., Rapoport, A., and Sychrova, H. (2015). The role of glycerol transporters in yeast cells in various physiological and stress conditions. FEMS Microbiol. Lett. 362, 1-8. doi: 10.1093/femsle/ fnu041

Duval, E. H., Alves, S. L., Dunn, B., Sherlock, G., and Stambuk, B. U. (2010) Microarray karyotyping of maltose-fermenting Saccharomyces yeasts with differing maltotriose utilization profiles reveals copy number variation in genes involved in maltose and maltotriose utilization. J. Appl. Microbiol. 109, 248-259. doi: 10.1111/j.1365-2672.2009.04656.x

Dzialo, M. C., Park, R., Steensels, J., Lievens, B., and Verstrepen, K. J. (2017). Physiology, ecology and industrial applications of aroma formation in yeast. FEMS Microbiol. Rev. 41, 95-128. doi: 10.1093/femsre/fux031

Ehrenreich, I. M., Gerke, J. P., and Kruglyak, L. (2009). Genetic Dissection of Complex Traits in Yeast: Insights from Studies of Gene Expression and Other Phenotypes in the BY $\times$ RM Cross. Cold Spring Harb. Symp. Quant. Biol. 74, 145-153. doi: 10.1101/sqb.2009.74.013

Ercolini, D., Pontonio, E., De Filippis, F., Minervini, F., La Storia, A., Gobbetti, M., et al. (2013). Microbial Ecology Dynamics during Rye and Wheat Sourdough Preparation. Appl. Environ. Microbiol. 79, 7827-7836. doi: 10.1128/AEM. 02955-13

Fay, J. C., Liu, P., Ong, G. T., Dunham, M. J., Cromie, G. A., Jeffery, E. W., et al. (2019). A polyploid admixed origin of beer yeasts derived from European and Asian wine populations. PLoS Biol. 17:3. doi: 10.1371/journal.pbio.3000147

Ferreira, C., van Voorst, F., Martins, A., Neves, L., Oliveira, R., Kielland-Brandt, M. C., et al. (2005). A Member of the Sugar Transporter Family, Stllp Is the Glycerol/H+ Symporter in Saccharomyces cerevisiae. Mol. Bio. Cell. 16, 2068-2076. doi: 10.1091/mbc.E04-10-0884

Fingolfn. Practically Science (2013). The Chemistry of Food Aromas. Available online at; https://www.practicallyscience.com/author/fingolfn/page/6/ (accessed July 15, 2020)

Fournier, T., Abou Saada, O., Hou, Jing, Peter, J., Caudal, E., et al. (2019). Extensive impact of low-frequency variants on the phenotypic landscape at population-scale. eLife 8:e49258. doi: 10.7554/eLife. 49258

Frasse, P., Lamberts, S., Richard-Molard, D., and Chiron, H. (1993). The Influence of Fermentation on Volatile Compounds in French Bread Dough. LWT Food Sci. Technol. 26, 126-132. doi: 10.1006/fstl.1993.1027

Frey, C. (1930). History and Development of the Modern Yeast Industry. Ind. Eng. Chem. 22, 1154-1162. doi: 10.1021/ie50251a012 
Gallone, B., Steensels, J., Mertens, S., Dzialo, M. C., Gordon, J. L., Wauters, R., et al. (2019). Interspecific hybridization facilitates niche adaptation in beer yeast. Nat. Ecol. Evol. 3, 1562-1575. doi: 10.1038/s41559-019-0997-9

Gallone, B., Steensels, J., Prahl, T., Soriaga, L., Saels, V., Herrera-Malaver, B., et al. (2016). Domestication and Divergence of Saccharomyces cerevisiae Beer Yeasts. Cell 166, 1397-1410. doi: 10.1016/j.cell.2016.08.020

Gélinas, P. (2010). Mapping Early Patents on Baker's Yeast Manufacture. Compr. Rev. Food Sci. Food Saf. 9, 483-497. doi: 10.1111/j.1541-4337.2010.00122.x

Glover, J. D., Reganold, J. P., Bell, L. W., Borevitz, J., Brummer, E. C., Buckler, E. S., et al. (2010). Increased Food and Ecosystem Security via Perennial Grains. Science 328, 1638-1639. doi: 10.1126/science.1188761

Gresham, D., Desai, M. M., Tucker, C. M., Jenq, H. T., Pai, D. A., Ward, A., et al. (2008). The repertoire and dynamics of evolutionary adaptations to controlled nutrient-limited environments in yeast. PLoS Genet. 4:12. doi: 10.1371/journal. pgen. 1000303

Grönberg, P.-O. (2019). The Peregrine Profession: Transnational Mobility of Nordic Engineers and Architects, 1880-1930. Netherlands: Koninklijke Brill NV., 140.

Gutiérrez, A., Beltran, G., Warringer, J., and Guillamón, J. M. (2013). Genetic Basis of Variations in Nitrogen Source Utilization in Four Wine Commercial Yeast Strains. PLoS One. 8:6. doi: 10.1371/journal.pone.0067166

Hahn, Y.-S., and Kawai, H. (1990). Isolation and Characterization of Freezetolerant Yeasts from Nature Available for the Frozen-dough Method. Agric. Biol. Chem. 54, 829-831. doi: 10.1271/bbb1961.54.829

Han, J., Lee, J.-D., Bibbs, L., and Ulevitch, R. J. (1994). A MAP Kinase Targeted by Endotoxin and Hyperosmolarity in Mammalian Cells. Science 265, 808-811.

Heitmann, M., Zannini, E., and Arendt, E. (2018). Impact of Saccharomyces cerevisiae metabolites produced during fermentation on bread quality parameters: A review. Crit. Rev. Food Sci. Nutr. 58, 1152-1164. doi: 10.1080/ 10408398.2016.1244153

Hernández-López, M. J., Prieto, J. A., and Randez-Gil, F. (2003). Osmotolerance and leavening ability in sweet and frozen sweet dough. Comparative analysis between Torulaspora delbrueckii and Saccharomyces cerevisiae baker's yeast strains. Anton. Leeuw. Int. J. G. 84, 125-134. doi: 10.1023/A:10254135 20192

Hino, A., Takano, H., and Tanaka, Y. (1987). New freeze-tolerant yeast for frozen dough preparations. Cereal Chem. 64, 265-275.

Hohmann, S. (2009). Control of high osmolarity signalling in the yeast Saccharomyces cerevisiae. FEBS Lett. 583, 4025-4029. doi: 10.1016/j.febslet. 2009.10.069

Hohmann, S., Krantz, M., and Nordlander, B. (2007). Yeast osmoregulation. Methods Enzymol. 428, 29-45. doi: 10.1016/S0076-6879(07)28002-4

Houghton-Larsen, J., and Brandt, A. (2006). Fermentation of High Concentrations of Maltose by Saccharomyces cerevisiae Is Limited by the COMPASS Methylation Complex. Appl. Environ. Microbiol. 72, 7176-7182. doi: 10.1128/ AEM.01704-06

Hsu, H. K., Hoseney, R. C., and Sib, P. A. (1979). Frozen dough. I. Factors affecting stability of yeasted doughs. Cereal Chem. 56, 419-424.

Jara, M., Cubillos, F. A., García, V., Salinas, F., Aguilera, O., Liti, G., et al. (2014). Mapping Genetic Variants Underlying Differences in the Central Nitrogen Metabolism in Fermenter Yeasts. PLoS One. 9:1. doi: 10.1371/journal.pone. 0086533

Johnson, L. J., Koufopanou, V., Goddard, M. R., Hetherington, R., Schäfer, S. M., and Burt, A. (2004). Population Genetics of the Wild Yeast Saccharomyces paradoxus. Genetics 166, 43-52. doi: 10.1534/genetics.166.1.43

Kaino, T., and Takagi, H. (2008). Gene expression profiles and intracellular contents of stress protectants in Saccharomyces cerevisiae under ethanol and sorbitol stresses. Appl. Microbiol. Biotechnol. 79, 273-283. doi: 10.1007/s00253008-1431-4

Kanter, J.-P., Benito, S., Brezina, S., Beisert, B., Fritsch, S., Patz, C.-D., et al. (2019). The impact of hybrid yeasts on the aroma profile of cool climate Riesling wines. Food Chem. 5:100072 doi: 10.1016/j.fochx.2019.100072

Keleher, C. A., Redd, M. J., Schultz, J., Clarson, M., and Johnson, A. D. (1992). Ssn6-Tup1 Is a General Repressor of Transcription in Yeast. Cell 68, 709-719. doi: 10.1016/0092-8674(92)90146-4

Kim, J., Alizadeh, P., Harding, T., Hefner-Gravink, A., and Klionsky, D. J. (1996). Disruption of the yeast ATH1 gene confers better survival after dehydration, freezing, and ethanol shock: potential commercial applications. Appl. Environ. Microbiol. 62, 1563-1569.
Kim, Y., Huang, W., Zhu, H., and Rayas-Duarte, P. (2009). Spontaneous sourdough processing of Chinese Northern-style steamed breads and their volatile compounds. Food Chem. 114, 685-692. doi: 10.1016/j.foodchem.2008. 10.008

Kishimoto, M. (1994). Fermentation characteristics of hybrids between the cryophilic wine yeast Saccharomyces bayanus and the mesophilic wine yeast Saccharomyces cerevisiae. J. Ferment. Bioeng. 77, 432-435. doi: 10.1016/0922338X(94)90019-1

Kopp, M., Müller, H., and Holzer, H. (1993). Molecular analysis of the neutral trehalase gene from Saccharomyces cerevisiae. J. Biol. Chem. 268, 4766-4774.

Koricha, A. D., Han, D.-Y., Bacha, K., and Bai, F.-Y. (2020). Diversity and distribution of yeasts in indigenous fermented foods and beverages of Ethiopia. J. Sci. Food Agric. 100, 3630-3638. doi: 10.1002/jsfa.10391

Langdon, Q. K., Peris, D., Baker, E. P., Opulente, D. A., Nguyen, H.-V., Bond, U., et al. (2019). Fermentation innovation through complex hybridization of wild and domesticated yeasts. Nat. Ecol. Evol. 3, 1576-1586. doi: 10.1038/s41559019-0998-8

Leroy, P., Sabri, A., Verheggen, F. J., Francis, F., Thonart, P., and Haubruge, R. (2011). The semiochemically mediated interactions between bacteria and insects. Chemoecology 21, 113-122. doi: 10.1007/s00049-011-0074-6

Lewis, J. G., Learmonth, R. P., Attfield, P. V., and Watson, K. (1997). Stress cotolerance and trehalose content in baking strains of Saccharomyces cerevisiae. J. Ind. Microbiol. Biotech. 18, 30-36. doi: 10.1038/sj.jim.2900347

Lhomme, E., Urien, C., Legrand, J., Dousset, X., Onno, B., and Sicard, D. (2016). Sourdough microbial community dynamics: An analysis during French organic bread-making processes. Food Microbiol. 53, 41-50. doi: 10.1016/j.fm.2014. 11.014

Li, Y., Chen, W., Shi, Y., and Liang, X. (2013). Molecular Cloning and Evolutionary Analysis of the HOG-Signaling Pathway Genes from Saccharomyces cerevisiae Rice Wine Isolates. Biochem. Genet. 51, 296-305. doi: 10.1007/s10528-0129563-8

Li, Z., Deng, C., Li, H., Liu, C., and Bian, K. (2015). Characteristics of remixed fermentation dough and its influence on the quality of steamed bread. Food Chem. 179, 257-262. doi: 10.1016/j.foodchem.2015.02.009

Li, Z., Li, H., and Bian, K. (2016). Microbiological characterization of traditional dough fermentation starter (Jiaozi) for steamed bread making by culturedependent and culture-independent methods. Int. J. Food Microbiol. 234, 9-14. doi: 10.1016/j.ijfoodmicro.2016.06.024

Ling, A. R. (1909). Prof. Emil Christian Hansen. Nature 81:310.

Liti, G., and Louis, E. J. (2012). Advances in Quantitative Trait Analysis in Yeast. PLoS Genet. 8:8. doi: 10.1371/journal.pgen.1002912

Liti, G., Carter, D. M., Moses, A. M., Warringer, J., Parts, L., James, S. A., et al. (2009). Population genomics of domestic and wild yeasts. Nature 458, 337-341. doi: 10.1038/nature07743

Liu, T., Li, Y., Sadiq, F. A., Yang, H., Gu, J., Lee, Y. K., et al. (2018). Predominant yeasts in Chinese traditional sourdough and their influence on aroma formation in Chinese steamed bread. Food Chem. 242, 404-411. doi: 10.1016/j.foodchem. 2017.09.081

Luo, W., Sun, D.-W., Zhu, Z., and Wang, Q.-J. (2018). Improving freeze tolerance of yeast and dough properties for enhancing frozen dough quality - A review of effective methods. Trends Food Sci. Tech. 72, 25-33. doi: 10.1016/j.tifs.2017. 11.017

Madden, A. A., Epps, M. J., Fukami, T., Irwin, R. E., Sheppard, J., Sorger, D. M., et al. (2018). The ecology of insect-yeast relationships and its relevance to human industry. Proc. Biol. Sci. 285:1875. doi: 10.1098/rspb.2017.2733

Mak, A., and Slate Magazine (2020). The Reason There's Still a Yeast Shortage. Washington, D.C: Slate Magazine.

Mangado, A., Morales, P., Gonzalez, R., and Tronchoni, J. (2018). Evolution of a Yeast With Industrial Background Under Winemaking Conditions Leads to Diploidization and Chromosomal Copy Number Variation. Front. Microbiol. 9:1816. doi: 10.3389/fmicb.2018.01816

Matsutani, K., Fukuda, Y., Murata, K., Kimura, A., Nakamura, I., and Yajima, N. (1990). Physical and biochemical properties of freeze-tolerant mutants of a yeast Saccharomyces cerevisiae. J. Ferment. Bioeng. 70, 275-276. doi: 10.1016/0922338X(90)90063-3

McCarron, M. (2020). Mar 25. So Everyone's Googling 'Bread' Now. Available online at: https://www.eater.com/2020/3/25/21194467/bread-tops-google-trendssearching-for-recipes (accessed June 30, 2020). 
Minervini, F., Lattanzi, A., De Angelis, M., Di Cagno, R., and Gobbetti, M. (2012). Influence of Artisan Bakery- or Laboratory-Propagated Sourdoughs on the Diversity of Lactic Acid Bacterium and Yeast Microbiotas. Appl. Environ. Microbiol. 78, 5328-5340. doi: 10.1128/AEM.00572-12

Mir, S. A., Naik, H. R., Shah, M. A., Mir, M. M., Wani, M. H., and Bhat, M. A. (2014). Indian Flat Breads: A Review. Food Nutr. Sci. 5, 549-561. doi: 10.4236/ fns.2014.56065

Mohd Azhar, S. H., Abdulla, R., Jambo, S. A., Marbawi, H., Gansau, J. A., Mohd Faik, A. A., et al. (2017). Yeasts in sustainable bioethanol production: A review. Biochem. Biophys. Rep. 10, 52-61. doi: 10.1016/j.bbrep.2017.03.003

Moussa, A. M., Altenmüller, H., and Johannes, D. (1977). Das Grab Des Nianchchnum Und Chnumhotep. Mainz am Rhein: von Zabern.

Nakagawa, S., and Ouchi, K. (1994). Construction from a single parent of baker's yeast strains with high freeze tolerance and fermentative activity in both lean and sweet doughs. Appl. Environ. Microbiol. 60, 3499-3502.

Naumov, G. I., Naumova, E. S., and Michels, C. A. (1994). Genetic variation of the repeated MAL loci in natural populations of Saccharomyces cerevisiae and Saccharomyces paradoxus. Genetics 136, 803-812.

Naumova, E. S., Sadykova, A. Z., Martynenko, N. N., and Naumov, G. I. (2013). Molecular genetic characteristics of Saccharomyces cerevisiae distillers' yeasts. Microbiology 82, 175-185. doi: 10.1134/S0026261713020112

Navas, M. A., Cerdán, S., and Gancedo, J. M. (1993). Futile cycles in Saccharomyces cerevisiae strains expressing the gluconeogenic enzymes during growth on glucose. Proc. Natl. Acad. Sci. U S A 90, 1290-1294. doi: 10.1073/pnas.90.4.1290

Nichols, L. (2020). Wild Sourdough. Available online at: http://robdunnlab.com/ projects/wildsourdough/ (accessed June 30, 2020).

Nikolaou, E., Agrafioti, I., Stumpf, M., Quinn, J., Stansfield, I., and Brown, A. J. P. (2009). Phylogenetic diversity of stress signalling pathways in fungi. BMC Evol. Biol. 9:44. doi: 10.1186/1471-2148-9-44

Nikulin, J., Krogerus, K., and Gibson, B. (2018). Alternative Saccharomyces interspecies hybrid combinations and their potential for low-temperature wort fermentation. Yeast 35, 113-127. doi: 10.1002/yea.3246

Nomura, M., and Takagi, H. (2004). Role of the yeast acetyltransferase Mpr1 in oxidative stress: Regulation of oxygen reactive species caused by a toxic proline catabolism intermediate. Proc. Natl. Acad. Sci. U S A 101, 12616-12621. doi: 10.1073/pnas.0403349101

Oliveira, B. M., Barrio, E., Querol, A., and Pérez-Torrado, R. (2014). Enhanced Enzymatic Activity of Glycerol-3-Phosphate Dehydrogenase from the Cryophilic Saccharomyces kudriavzevii. PLoS One 9:e87290. doi: 10.1371/ journal.pone.0087290

Oliveira, R., Lages, F., Silva-Graça, M., and Lucas, C. (2003). Fpslp channel is the mediator of the major part of glycerol passive diffusion in Saccharomyces cerevisiae: artefacts and re-definitions. BBA Biomembr. 1613, 57-71. doi: 10 . 1016/S0005-2736(03)00138-X

Olsson, L., and Nielsen, J. (2000). The role of metabolic engineering in the improvement of Saccharomyces cerevisiae: utilization of industrial media. Enzyme Microb. Tech. 26, 785-792. doi: 10.1016/s0141-0229(00)00172-1

Padilla, B., Gil, J. V., and Manzanares, P. (2016). Past and Future of NonSaccharomyces Yeasts: From Spoilage Microorganisms to Biotechnological Tools for Improving Wine Aroma Complexity. Front. Microbiol. 7:411. doi: 10.3389/fmicb.2016.00411

Palla, M., Blandino, M., Grassi, A., Giordano, D., Sgherri, C., Quartacci, M. F., et al. (2020). Characterization and selection of functional yeast strains during sourdough fermentation of different cereal wholegrain flours. Sci. Rep. 10:12856. doi: 10.1038/s41598-020-69774-6

Payen, C., Di Rienzi, S. C., Ong, G. T., Pogachar, J. L., Sanchez, J. C., Sunshine, A. B., et al. (2014). The dynamics of diverse segmental amplifications in populations of Saccharomyces cerevisiae adapting to strong selection. G3 4, 399-409. doi: $10.1534 / g 3.113 .009365$

Perez-Samper, G., Cerulus, B., Jariani, A., Vermeersch, L., Barrajón Simancas, N., Bisschops, M. M. M., et al. (2018). The Crabtree Effect Shapes the Saccharomyces cerevisiae Lag Phase during the Switch between Different Carbon Sources. mBio 9:e01331-18. doi: 10.1128/mBio.01331-18

Pérez-Través, L., Lopes, C. A., Barrio, E., and Querol, A. (2012). Evaluation of different genetic procedures for the generation of artificial hybrids in Saccharomyces genus for winemaking. Int. J. Food Microbiol. 156, 102-111. doi: 10.1016/j.ijfoodmicro.2012.03.008
Peris, D., Moriarty, R. V., Alexander, W. G., Baker, E., Sylvester, K., Sardi, M., et al. (2017). Hybridization and adaptive evolution of diverse Saccharomyces species for cellulosic biofuel production. Biotechnol. Biofuels 10:78. doi: 10.1186/ s13068-017-0763-7

Pétel, C., Onno, B., and Prost, C. (2017). Sourdough volatile compounds and their contribution to bread: A review. Trends Food Sci. Technol. 59, 105-123. doi: 10.1016/j.tifs.2016.10.015

Peter, J., De Chiara, M., Friedrich, A., Yue, J.-X., Pflieger, D., Bergström, A., et al. (2018). Genome evolution across 1,011 Saccharomyces cerevisiae isolates. Nature 556, 339-344. doi: 10.1038/s41586-018-0030-5

Pico, J., Bernal, J., and Gómez, M. (2015). Wheat bread aroma compounds in crumb and crust: A review. Food Res. Int. 75, 200-215. doi: 10.1016/j.foodres. 2015.05.051

Pliny the Elder, "The natural history book XVIII - The natural history of grain," in Chap. 28 - When Bakers Were First Introduced at Rome, eds J. Bostock, and H. T. Riley (Perseus Digital Library). Available online at: http://data.perseus.org/ citations/urn:cts:latinLit:phi0978.phi001.perseus-eng1:18.28 (accessed May 15, 2020).

Pulvirenti, A., Solieri, L., Gullo, M., Vero, L. D., and Giudici, P. (2004). Occurrence and dominance of yeast species in sourdough. Lett. Appl. Microbiol. 38, 113117. doi: 10.1111/j.1472-765X.2003.01454.X

Raingeaud, J., Gupta, S., Rogers, J. S., Dickens, M., Han, J., Ulevitch, R. J., et al. (1995). Pro-inflammatory Cytokines and Environmental Stress Cause p38 Mitogen-activated Protein Kinase Activation by Dual Phosphorylation on Tyrosine and Threonine. J. Biol. Chem. 270, 7420-7426. doi: 10.1074/jbc.270. 13.7420

Randez-Gil, F., Córcoles-Sáez, I., and Prieto, J. A. (2013). Genetic and Phenotypic Characteristics of Baker's Yeast: Relevance to Baking. Annu. Rev. Food Sci. Technol. 4, 191-214. doi: 10.1146/annurev-food-030212-182609

Reese, A. T., Madden, A. A., Marie, J., Guylaine, L., and Dunn, R. R. (2020). Influences of Ingredients and Bakers on the Bacteria and Fungi in Sourdough Starters and Bread. $m$ Sphere 5, e00950-19. doi: 10.1128/mSphere.00950-19

Reuter, M., Bell, G., and Greig, D. (2007). Increased outbreeding in yeast in response to dispersal by an insect vector. Curr. Biol. 17, 81-83. doi: 10.1016/ j.cub.2006.11.059

Richard, P., Bakker, B. M., Teusink, B., Van Dam, K., and Westerhoff, H. V. (1996). Acetaldehyde mediates the synchronization of sustained glycolytic oscillations in populations of yeast cells. Eur. J. Biochem. 235, 238-241. doi: 10.1111/j.14321033.1996.00238.x

Salvadó, Z., Arroyo-López, F. N., Guillamón, J. M., Salazar, G., Querol, A., and Barrio, E. (2011). Temperature Adaptation Markedly Determines Evolution within the Genus Saccharomyces. Appl. Environ. Microbiol. 77, 2292-2302. doi: 10.1128/AEM.01861-10

Samuel, D. (1989). “Their staff of life: initial investigations on ancient Egyption bread baking," in Amarna Reports V, Occasional Publications 6, ed. B. J. Kemp (London: Egypt Exploration Society), 253-290.

Samuel, D. (1996). Investigation of Ancient Egyptian Baking and Brewing Methods by Correlative Microscopy. Science 273, 488-490. doi: 10.1126/science.273. 5274.488

Samuel, D., Kumar, T. K., Ganesh, G., Jayaraman, G., Yang, P. W., Chang, M. M., et al. (2000). Proline inhibits aggregation during protein refolding. Protein Sci. 9, 344-352. doi: 10.1110/ps.9.2.344

Sasano, Y., Haitani, Y., Hashida, K., Ohtsu, I., Shima, J., and Takagi, H. (2012a). Simultaneous accumulation of proline and trehalose in industrial baker's yeast enhances fermentation ability in frozen dough. J. Biosci. Bioeng. 113, 592-595. doi: 10.1016/j.jbiosc.2011.12.018

Sasano, Y., Haitani, Y., Ohtsu, I., Shima, J., and Takagi, H. (2012b). Proline accumulation in baker's yeast enhances high-sucrose stress tolerance and fermentation ability in sweet dough. Int. J. Food Microbiol. 152, 40-43. doi: 10.1016/j.ijfoodmicro.2011.10.004

Sasano, Y., Takahashi, S., Shima, J., and Takagi, H. (2010). Antioxidant $\mathrm{N}$-acetyltransferase Mpr1/2 of industrial baker's yeast enhances fermentation ability after air-drying stress in bread dough. Int. J. Food Microbiol. 138, 181-185. doi: 10.1016/j.ijfoodmicro.2010.01.001

Sato, T. K., Tremaine, M., Parreiras, L. S., Hebert, A. S., Myers, K. S., Higbee, A. J., et al. (2016). Directed Evolution Reveals Unexpected Epistatic Interactions That Alter Metabolic Regulation and Enable Anaerobic Xylose 
Use by Saccharomyces cerevisiae. PLoS Genet. 12:10. doi: 10.1371/journal.pgen. 1006372

Schaaff, I., Heinisch, J., and Zimmermann, F. K. (1989). Overproduction of glycolytic enzymes in yeast. Yeast 5, 285-290. doi: 10.1002/yea.320050408

Schieberle, P., and Grosch, W. (1991). Potent odorants of the wheat bread crumb Differences to the crust and effect of a longer dough fermentation. Z. Lebensm. Unters. Forch. 192, 130-135. doi: 10.1007/BF01202626

Sekine, T., Kawaguchi, A., Hamano, Y., and Takagi, H. (2007). Desensitization of Feedback Inhibition of the Saccharomyces cerevisiae $\gamma$-Glutamyl Kinase Enhances Proline Accumulation and Freezing Tolerance. Appl. Environ. Microbiol. 73, 4011-4019. doi: 10.1128/AEM.00730-07

Selmecki, A. M., Maruvka, Y. E., Richmond, P. A., Guillet, M., Shoresh, N., Sorenson, A. L., et al. (2015). Polyploidy can drive rapid adaptation in yeast. Nature 519, 349-352. doi: 10.1038/nature14187

Sheppard, J., Dunn, R. R., and Madden, A. A. (2015). Methods for the production of fermented beverages and other fermentation products. US Patent Application No. US 20,180,119,074 A1. Washington, DC: U.S. Patent and Trademark Office.

Shevchenko, A., Yang, Y., Knaust, A., Thomas, H., Jiang, H., Lu, E., et al. (2014). Proteomics identifies the composition and manufacturing recipe of the 2500year old sourdough bread from Subeixi cemetery in China. J. Proteomics 105, 363-371. doi: 10.1016/j.jprot.2013.11.016

Shima, J., Hino, A., Yamada-Iyo, C., Suzuki, Y., Nakajima, R., Watanabe, H., et al. (1999). Stress Tolerance in Doughs of Saccharomyces cerevisiae Trehalase Mutants Derived from Commercial Baker's Yeast. Appl. Environ. Microbiol. 65, 2841-2846. doi: 10.1128/AEM.65.7.2841-2846

Sicard, D., and Legras, J. (2011). Bread, beer, and wine: Yeast domestication in the Saccharomyces sensu stricto complex. C. R. Biol. 334, 229-236. doi: 10.1016/j. crvi.2010.12.016

Sipiczki, M. (2008). Interspecies hybridization and recombination in Saccharomyces wine yeasts. FEMS Yeast Res. 8, 996-1007. doi: 10.1111/j.1567-1364.2008.00369.x

Smukowski Heil, C. S., DeSevo, C. G., Pai, D. A., Tucker, C. M., Hoang, M. L., and Dunham, M. J. (2017). Loss of Heterozygosity Drives Adaptation in Hybrid Yeast. Mol. Biol. Evol. 34, 1596-1612. doi: 10.1093/molbev/msx098

Spor, A., Nidelet, T., Simon, J., Bourgais, A., de Vienne, D., and Sicard, D. (2009). Niche-driven evolution of metabolic and life-history strategies in natural and domesticated populations of Saccharomyces cerevisiae. BMC Evol. Biol. 9:296. doi: 10.1186/1471-2148-9-296

Steensels, J., and Verstrepen, K. J. (2014). Taming wild yeast: potential of conventional and nonconventional yeasts in industrial fermentations. Аnпи. Rev. Microbiol. 68, 61-80. doi: 10.1146/annurev-micro-091213-113025

Steensels, J., Meersman, E., Snoek, T., Saels, V., and Vestrepen, K. J. (2014a). Large-Scale Selection and Breeding To Generate Industrial Yeasts with Superior Aroma Production. Appl. Environ. Microbiol. 80, 6965-6975. doi: 10.1128/ AEM.02235- 14

Steensels, J., Snoek, T., Meersman, E., Nicolino, M. P., Voordeckers, K., and Verstrepen, K. J. (2014b). Improving industrial yeast strains: exploiting natural and artificial diversity. FEMS Microbiol. Rev. 38, 947-995. doi: 10.1111/15746976.12073

Stefanini, I., Dapporto, L., Berná, L., Polsinelli, M., Turillazzi, S., and Cavalieri, D. (2016). Social wasps are a Saccharomyces mating nest. Proc. Natl. Acad. Sci. U S A 113, 2247-2251. doi: 10.1073/pnas.1516453113

Styger, G., Jacobson, D., and Bauer, F. F. (2011). Identifying genes that impact on aroma profiles produced by Saccharomyces cerevisiae and the production of higher alcohols. Appl. Microbiol. Biotechnol. 91, 713-730. doi: 10.1007/s00253011-3237-z

Suárez-Lepe, J. A., and Morata, A. (2012). New trends in yeast selection for winemaking. Trends Food Sci. Tech. 23, 39-50. doi: 10.1016/j.tifs.2011.08.005

Sunshine, A. B., Payen, C., Ong, G. T., Liachko, I., Tan, K. M., and Dunham, M. J. (2015). The fitness consequences of aneuploidy are driven by conditiondependent gene effects. PLoS Biol. 13:e1002155.

Swinnen, S., Schaerlaekens, K., Pais, T., Claesen, J., Hubmann, G., Yang, Y., et al. (2012). Identification of novel causative genes determining the complex trait of high ethanol tolerance in yeast using pooled-segregant whole-genome sequence analysis. Genome Res. 22, 975-984. doi: 10.1101/gr.131698.111

Sylvester, K., Qi-Ming, W., Brielle, J., Mendez, R., Hulfachor, A. B., and Hittinger, C. T. (2015). Temperature and host preferences drive the diversification of
Saccharomyces and other yeasts: a survey and the discovery of eight new yeast species. FEMS Yeast Res. 15:fov002. doi: 10.1093/femsyr/fov002

Tadesse, B. T., Abera, A. B., Tefera, A. T., Muleta, D., Alemu, Z. T., and Wessel, G. (2019). Molecular Characterization of Fermenting Yeast Species from Fermented Teff Dough during Preparation of Injera Using ITS DNA Sequence. Int. J. Food Sci. 2019:1291863. doi: 10.1155/2019/1291863

Takagi, H. (2008). Proline as a stress protectant in yeast: physiological functions, metabolic regulations, and biotechnological applications. Appl. Microbiol. Biotechnol. 81, 211-223. doi: 10.1007/s00253-008-1698-5

Takagi, H. (2017). "Construction of Baker's Yeast Strains with Enhanced Tolerance to Baking-Associated Stresses," in Biotechnology of Yeasts and Filamentous Fungi, ed. A. A. Sibirny (Cham: Springer International Publishing).

Takagi, H., Iwamoto, F., and Nakamori, S. (1997). Isolation of freeze-tolerant laboratory strains of Saccharomyces cerevisiae from proline-analogue-resistant mutants. Appl. Microbiol. Biotechnol. 47, 405-411. doi: 10.1007/s00253005 0948

Tamang, J. P., Thapa, N., Bhalla, T. C., and Savitri. (2016). "Ethnic Fermented Foods and Beverages of India," in Ethnic Fermented Foods and Alcoholic Beverages of Asia, ed. J. P. Tamang (New Delhi: Springer India), 17-42.

Thorsen, M., Di, Y., Tängemo, C., Morillas, M., Ahmadpour, D., Van der Does, C., et al. (2006). The MAPK Hoglp Modulates Fps1p-dependent Arsenite Uptake and Tolerance in Yeast. Mol. Biol. Cell 17, 4400-4410. doi: 10.1091/mbc.E0604-0315

Treitel, M. A., and Carlson, M. (1995). Repression by SSN6-TUP1 is directed by MIG1, a repressor/activator protein. Proc. Natl. Acad. Sci. U S A. 92, 3132-3136. doi: 10.1073/pnas.92.8.3132

Tsolmonbaatar, A., Hashida, K., Sugimoto, Y., Watanabe, D., Furukawa, S., and Takagi, H. (2016). Isolation of baker's yeast mutants with proline accumulation that showed enhanced tolerance to baking-associated stresses. Int. J. Food Microbiol. 238, 233-240. doi: 10.1016/j.ijfoodmicro.2016.09.015

Urbina, H., Frank, R., and Blackwell, M. (2013). Scheffersomyces cryptocercus: a new xylose-fermenting yeast associated with the gut of wood roaches and new combinations in the Sugiyamaella yeast clade. Mycologia 105, 650-660. doi: 10.3852/12-094

Verberg, S. (2019). Scandinavian Yeast Rings: The Curious Case of the Twisted Torus. Brewery His. 178, 49-61.

Vermeersch, L., Perez-Samper, G., Cerulus, B., Jariani, A., Gallone, B., Voordeckers, K., et al. (2019). On the duration of the microbial lag phase. Curr. Genet. 65, 721-727. doi: 10.1007/s00294-019-00938-2

Vrancken, G., De Vuyst, L., Van der Meulen, R., Huys, G., Vandamme, P., and Daniel, H.-M. (2010). Yeast species composition differs between artisan bakery and spontaneous laboratory sourdoughs. FEMS Yeast Res. 10, 471-481. doi: 10.1111/j.1567-1364.2010.00621.x

Wang, Q.-M., Liu, W.-Q., Liti, G., Wang, S.-A., and Bai, F.-Y. (2012). Surprisingly diverged populations of Saccharomyces cerevisiae in natural environments remote from human activity. Mol. Ecol. 21, 5404-5417. doi: 10.1111/j.1365294X.2012.05732.X

Wang, Y., Halls, C., Zhang, J., Matsuno, M., Zhang, Y., and Yu, O. (2011). Stepwise increase of resveratrol biosynthesis in yeast Saccharomyces cerevisiae by metabolic engineering. Metabol. Eng. 13, 455-463. doi: 10.1016/j.ymben. 2011.04.005

Warringer, J., Zörgö, E., Cubillos, F. A., Zia, A., Gjuvsland, A., Simpson, J. T., et al. (2011). Trait Variation in Yeast Is Defined by Population History. PLoS Genet. 7:e1002111. doi: 10.1371/journal.pgen.1002111

Wedral, D., Shewfelt, R., and Frank, J. (2010). The challenge of Brettanomyces in wine. LWT Food Sci. Technol. 43, 1474-1479. doi: 10.1016/j.lwt.2010. 06.010

Wilkening, S., Lin, G., Fritsch, E. S., Tekkedil, M. M., Anders, S., Kuehn, R., et al. (2014). An Evaluation of High-Throughput Approaches to QTL Mapping in Saccharomyces cerevisiae. Genetics 196, 853-865. doi: 10.1534/genetics.113. 160291

Wu, X., Chi, X., Wang, P., Zheng, D., Ding, R., and Li, Y. (2010). The evolutionary rate variation among genes of HOG-signaling pathway in yeast genomes. Biol. Direct. 5:46. doi: 10.1186/1745-6150-5-46

Xi, S., Zhang, C.-Y., Wu, M.-Y., Fan, Z.-H., Liu, S.-N., Zhu, W.-B., et al. (2016). MAL62 overexpression and NTH1 deletion enhance the freezing tolerance and fermentation capacity of the bakers yeast 
in lean dough. Microb. Cell Fact 15:54. doi: 10.1186/s12934-0160453-3

Zambonelli, C., Passarelli, P., Rainieri, S., Bertolini, L., Giudici, P., and Castellari, L. (1997). Technological Properties and Temperature Response of Interspecific Saccharomyces Hybrids. J. Sci. Food Agric. 74, 7-12. doi: 10.1002/(SICI)1097-0010(199705)74:1<7::AID-JSFA753<3. $0 . \mathrm{CO} ; 2-\mathrm{X}$

Zhang, J., Liu, W., Sun, Z., Bao, Q., Wang, F., Yu, J., et al. (2011). Diversity of lactic acid bacteria and yeasts in traditional sourdoughs collected from western region in Inner Mongolia of China. Food Control 22, 767-774.
Conflict of Interest: The authors declare that the research was conducted in the absence of any commercial or financial relationships that could be construed as a potential conflict of interest.

Copyright (C) 2020 Lahue, Madden, Dunn and Smukowski Heil. This is an open-access article distributed under the terms of the Creative Commons Attribution License (CC BY). The use, distribution or reproduction in other forums is permitted, provided the original author(s) and the copyright owner(s) are credited and that the original publication in this journal is cited, in accordance with accepted academic practice. No use, distribution or reproduction is permitted which does not comply with these terms. 